\title{
Pleiotropic Functions of Cytochrome P450 Monooxygenase-Derived Eicosanoids in Cancer
}

\author{
Ying Luo ${ }^{1}$ and Jun-Yan Liu ${ }^{2 * t}$ \\ ${ }^{1}$ Department of Clinical Laboratory, Changning Maternity and Infant Health Hospital, East China Normal University, Shanghai, \\ China, ${ }^{2}$ Center for Novel Target \& Therapeutic Intervention, Institute of Life Sciences, Chongqing Medical University, Chongqing, \\ China
}

Eicosanoids are a class of functionally bioactive lipid mediators derived from the metabolism of long-chain polyunsaturated fatty acids (PUFAs) mediated by multiple enzymes of three main branches, including cyclooxygenases (COXs), lipoxygenases (LOXs), and cytochrome P450s (CYPs). Recently, the role of eicosanoids derived by COXs and LOXs pathways in the control of physiological and pathological processes

OPEN ACCESS

Edited by:

Emer Smyth,

University of Pennsylvania,

United States

Reviewed by:

Milena Sokolowska,

University of Zurich, Switzerland

Jiiang-Huei Jeng,

National Taiwan University,

Taiwan

*Correspondence:

Jun-Yan Liu

jyliu@cqmu.edu.cn

${ }^{\dagger} \mathrm{ORCID:}$

Jun-Yan Liu

orcid.org/0000-0002-3018-0335

Specialty section:

This article was submitted to Inflammation Pharmacology,

a section of the journal

Frontiers in Pharmacology

Received: 07 July 2020 Accepted: 30 September 2020

Published: 29 October 2020

Citation:

Luo Y and LiU J-Y (2020) Pleiotropic

Functions of Cytochrome

P450 Monooxygenase-Derived

Eicosanoids in Cancer.

Front. Pharmacol. 11:580897.

doi: 10.3389/fphar.2020.580897 associated with cancer has been well documented. However, the role of CYPs-mediated eicosanoids, such as epoxyeicosatrienoic acids (EETs), epoxyoctadecenoic acids (EpOMEs), epoxyeicosatetraenoic acids (EpETEs), and epoxydocosapentaenoic acids (EDPs), as well as hydroxyeicosatetraenoic acids (HETEs), in tumorigenesis and cancer progression have not been fully elucidated yet. Here we summarized the association of polymorphisms of CYP monooxygenases with cancers and the pleiotropic functions of CYP monooxygenase-mediated eicosanoids (EETs, EpOMEs, EpETE, EDPs, and 20HETE) in the tumorigenesis and metastasis of multiple cancers, including but not limited to colon, liver, kidney, breast and prostate cancers, which hopefully provides valuable insights into cancer therapeutics. We believe that manipulation of CYPs with or without supplement of $\omega$-3 PUFAs to regulate eicosanoid profile is a promising strategy to prevent and/or treat cancers.

Keywords: CYP = cytochrome P450, eicosanoid, cancer, morphism, mechanism
Abbreviations: AA, arachidonic acid; ALA, $a$-linolenic acid; ALL, acute lymphoblastic leukemia; AOM/DSS, azoxymethane/dextran sodium sulfate; CML, chronic myelogenous leukemia; COX, cyclooxygenase; CRC, colorectal cancer; CYP, cytochrome P450; DHA, docosahexaenoic acid; DHET, dihydroxyeicosatrienoic acid; DiHOME, dihydroxyoctadecenoic acid; EDP or EpDPE, epoxydocosapentaenoic acid; EEQ or EpETE, epoxyeicosatetraenoic acid; EET, epoxyeicosatrienoic acid; EGF, epidermal growth factor ; EMT, epithelial-mesenchymal transition; EPA, eicosatetraenoic acid; EpOME, epoxyoctadecenoic acid; FGF, fibroblast growth factor; GIST, gastrointestinal stromal tumors; GLA, $\gamma$-linolenic acid; HCC, hepatocellular carcinoma; HDoHE, hydroxydocosahexaenoic acid; HEPE, hydroxyeicosapentaenoic acid; HETE, hydroxyeicosatetraenoic acid; HNSCC, head and neck squamous cell carcinoma; LA, linoleic acid; LOX, lipoxygenase; $\mathrm{mEH}$, microsomal epoxide hydrolase; NSCLC, non-small cell lung cancer; PDGF, platelet-derived growth factor; $\mathrm{PLA}_{2}$, phospholipase $\mathrm{A}_{2}$; PPAR, peroxisome proliferator-activated receptor; PUFA, polyunsaturated fatty acid; RA, retinoic acid; $\mathrm{SEH}$, soluble epoxide hydrolase; SREBP, sterol regulatory element binding protein; TNBC, triple-negative breast cancer; TNFa, tumor necrosis factor- $\alpha$. 


\section{INTRODUCTION}

Eicosanoids, a class of bioactive lipid mediators, are the metabolites of long-chain n-3 and n-6 polyunsaturated fatty acids (PUFAs) mediated by three primary enzymatic systems, cyclooxygenases (COXs), lipoxygenases (LOXs), and cytochrome P450s (CYPs) enzymes. The common PUFAs include arachidonic acid (20:4 n =6, AA), linoleic acid (18:2 $n=6$, LA), $\gamma$-linolenic acid (18:3 n=6, GLA), $\alpha$-linolenic acid (18:3 $\mathrm{n}=3$, ALA), eicosatetraenoic acid (20:5 n = 3, EPA) and docosahexaenoic acid (22:6 n = 3, DHA). Eicosanoids are synthesized rapidly in response to multiple factors (e.g. allergy, infection, and injury) and act putatively through their cognate receptors in local cells. Although some eicosanoids exhibit immediate and short-lasting activity, they play an important role in many chronic diseases, including asthma, allergy, autoimmune diseases, and malignancies since they have pleiotropic functions, such as pro-inflammation, anti-inflammation, vasodilation, analgesia, and hyperalgesia (Dennis and Norris, 2015; Sokolowska et al., 2020). Interestingly, some eicosanoids were found to have dual actions, for example, lipoxins, resolvins, and protectins, which have been extensively reported to be anti-inflammatory and pro-resolving (Serhan et al., 2008). Emerging evidence showed the dominant roles of metabolites of PUFAs involved in the regulation of inflammation, pain, angiogenesis, and cancer (Zhang et al., 2014a). The COX- and LOX-mediated PUFAs metabolism have been well documented in tumorigenesis and cancer progression (Wang and Dubois, 2006; Cathcart et al., 2012; Knab et al., 2014; Tuncer and Banerjee, 2015). However, the roles of the CYP pathway-mediated metabolites of PUFAs in the pathogenesis of cancer has not been fully studied.

CYP enzymes catalyze a variety of oxidative and some reductive reactions involving thousands of substrates (Guengerich, 2007). The substrates of CYPs encompass xenobiotics, including substances that occur biologically but are exogenous to humans, such as antibiotics and synthetic organic chemicals (Porter and Coon, 1991), and endogenous compounds, such as cholesterol, testosterone, progesterone, prostaglandin $\mathrm{H}_{2}$, corticosterone, retinoic acid, vitamin $\mathrm{D}_{3}$, and some PUFAs, like $\mathrm{AA}$ and LA (Guengerich, 2017). CYP enzymes can mediate the metabolisms of the lipophilic endogenous and xenobiotic compounds into hydrophilic or polar compounds, which could be excreted from the body easily (Chang and Kam, 1999). Firstly, the substrate binds to the active sites of CYP enzymes. Then the reductive reaction of the heme iron from a ferric to a ferrous is occurred by an electron transferred from a reduced NADPH (Chang and Kam, 1999). After that, the oxygen molecule temporarily binds at the heme-containing active site (Zanger and Schwab, 2013). At last, the substrate molecule is inserted by an oxygen atom, and water is formed by other relevant atoms simultaneously. Therefore, CYP monooxygenases incorporate one atom of oxygen into their substrates (Ortiz de Montellano, 2010). Here we focus on the CYP-derived metabolites of PUFAs and their multiple functions in cancer.

\section{The Cytochrome P450-Derived Eicosanoids of n-6 Polyunsaturated Fatty Acids}

CYPs consisting of 57 functional genes in human are a superfamily of enzymes which mediate the metabolism of exogenous and endogenous compounds (Jamieson et al., 2017; Nelson et al., 2004). AA and LA are the most common substrates of the CYP enzyme system. CYP enzymes relevant to AA metabolism include two main branches: the $\omega$-hydroxylase and epoxygenase pathways (Panigrahy et al., 2010). Epoxygenases (mainly CYP2C and CYP2J isoforms) convert AA to epoxyeicosatrienoic acids (EETs), including 5(6)-, 8(9)-, 11(12)-, and 14(15)-EET (Wu et al., 1997). $\omega$-hydroxylases (mainly CYP4A and CYP4F isoforms) convert AA to 19-, and 20-hydroxyeicosatetraenoic acids (HETEs) (Figure 1) (Panigrahy et al., 2010). In addition, CYP4X1 and CYP2U1 can metabolize AA to 19- and 20-HETE, as well as 8(9)-, and 14(15)-EET (Chuang et al., 2004; Stark et al., 2008). LA is the primary exogenous precursor of essential fatty acids, obtained from many diets. Within the body, LA can be catalyzed to the formation of 9(10)- and 12(13)-epoxyoctadecenoic acids (EpOMEs) in the presence of CYP epoxygenases. Both EETs and EpOMEs are metabolically unstable and can be rapidly metabolized to corresponding fatty acid diols, dihydroxyeicosatrienoic acids (DHETs), and dihydroxyoctadecenoic acid (DiHOMEs), respectively, by soluble epoxide hydrolase $(\mathrm{sEH})$ and microsomal EH (mEH) (Figure 1) (Zhang et al., 2014a). Recently, the CYP/sEH eicosanoid pathway related to inflammation and cancer gains many interests in academic researches.

\section{The Cytochrome P450-Derived Eicosanoids of n-3 Polyunsaturated Fatty Acids}

The n-3 PUFAs, mainly EPA and DHA, can be catalyzed by CYP isozymes into functional eicosanoids. EPA is metalized into $\omega /(\omega-1)$-hydroxyeicosapentaenoic acids (19- and 20-HEPE) by CYP $\omega$-hydroxylases, and five regioisomeric epoxyeicosatetraenoic acids [5(6)-, 8(9)-, 11(12)-, 14(15)-, 17(18)-EEQ, or EpETE] by CYP epoxygenases (Figure 1) (Van Rollins et al., 1988). DHA can also be metalized into $\omega /(\omega-1)$-hydroxydocosahexaenoic acids (21- and 22-HDoHE) by CYP $\omega$-hydroxylases, and six regioisomeric epoxydocosapentaenoic acids [4(5)-, 7(8)-, 10(11)-, 13(14)-, 16(17)-, 19(20)-EDP, or EpDPE), respectively, by CYP epoxygenases (Figure 1) (VanRollins et al., 1984). The epoxy metabolites EEQ and EDP can be further metabolized by sEH and $\mathrm{mEH}$ enzyme to the corresponding diols.

\section{The Presence and Location of Cytochrome P450s in Organs}

The CYP superfamily comprises 57 functional CYP genes and 58 pseudogenes in humans (Nelson et al., 2004). The CYPs have been reported to express in all human tissues investigated (Porter and Coon, 1991). They are expressed predominately in the endoplasmic reticulum membrane, cell surface, and mitochondria (Neve and Ingelman-Sundberg, 2010), with the greatest abundance in the liver (Porter and Coon, 1991), small intestine (Thelen and Dressman, 2009), and kidney (Renaud et al., 2011).

In humans, CYP2C and CYP2J are the predominant epoxygenases that metabolize PUFAs. CYP2C and CYP2J are widely distributed in the human body, including but not limited 
A

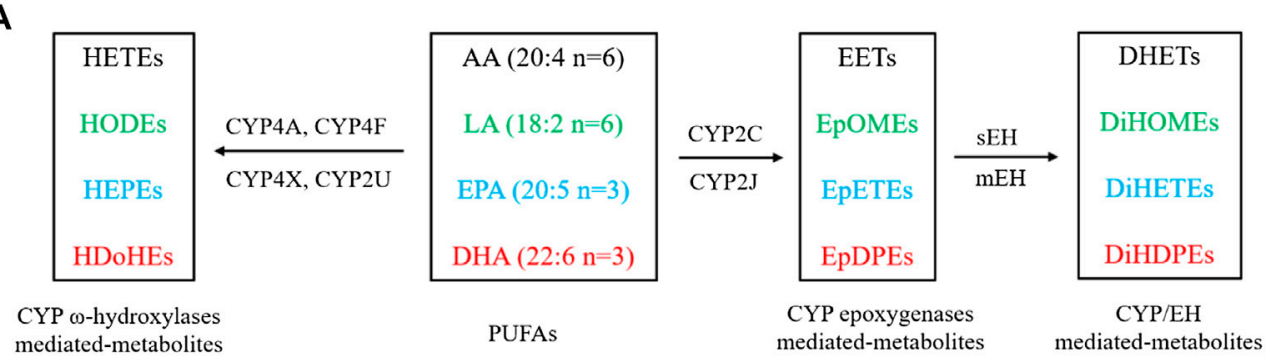

B
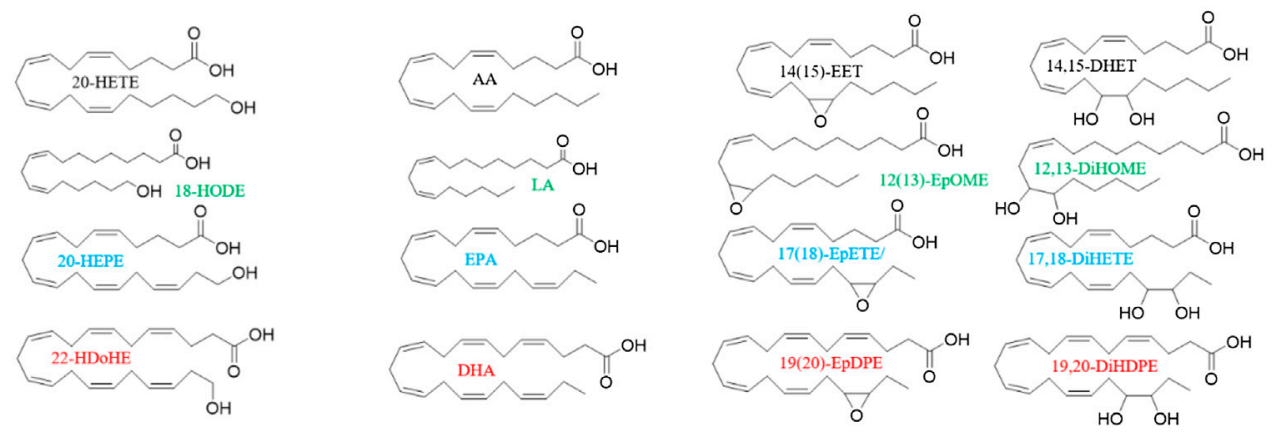

FIGURE 1 | Metabolism of PUFAs by CYP enzymes. (A) A simplified cascade of PUFAs discussed in this paper. AA, arachidonic acid; LA, linoleic acid; EPA, eicosapentaenoic acid; DHA, docosahexaenoic acid; CYP, cytochrome P450; sEH, soluble epoxide hydrolase; DHET, dihydroxyeicosatrienoic acid; DiHOME, dihydroxy octadecamonoeneoic acid; DiHETE, dihydroxyeicosatetraenoic acid; DiHDTE, dihydroxydocosatetraenoic acid; EET, epoxyeicosatrienoic acid; EpOME, epoxyoctadecamonoeneoic acid; EEQ or EpETE, epoxyeicosatetreaenoic acid; EDP or EpDPE, epoxydocosapentaenoic acid; HDoHE, hydroxydocosahexaenoic acid; HEPE: hydroxyeicosapentaenoic acid; HETE, hydroxyeicosatetraenoic acid; HODE, hydroxyoctadecadienoic acid; mEH, microsomal epoxide hydrolase; sEH, soluble epoxide hydrolase. The metabolites are from the fatty acids in the same color. (B) The chemical structures of PUFAs and the representative metabolites.

to the cardiovascular system, kidney, lung, brain, gastrointestinal tract, cerebral cortex, hippocampus, fetal nasal mucosa, and many other tissues (Nelson et al., 2004). The CYP2C family is located on chromosome 10 and consists of at least seven genes and/or pseudogenes. The CYP2C8, CYP2C9, CYP2C18, and CYP2C19 are most involved in the metabolism of PUFAs. They are also convinced to be involved in the progression of a malignant tumor (Xu et al., 2011). Besides the abovementioned four CYP2C enzymes, CYP2J2 is another epoxygenase acting as a regulator that catalyzes the metabolism of PUFAs. In the human body, CYP2J2 is mainly distributed in cardiovascular tissues, such as cardiomyocytes, coronary endothelial cells, and aorta and vein of coronary smooth muscle cells. Liver enzymes account for only 1-2\% of total CYP in the liver, jejunum, ileum, and colon. Limited by its content, CYP2J2 generally does not play a decisive role in exogenous metabolism in theory. However, CYP2J2 has been found to play a dominant role in the intestinal metabolism of certain drugs, such as antihistamines, terfenadine, and ebastine. In the kidney, CYP2J2 is expressed in proximal convoluted tubule and collecting tubule. In addition to the expression in tissues such as the heart, kidney, and liver, CYP2J2 is also highly expressed in the cerebral cortex, frontal lobe, and hippocampus. Dutheil et al. showed that a variety of CYPs are distributed in the human brain, and the expression level of CYP2J2 is about $20 \%$ of the total content of CYPs. Moreover, Ahmed E. et al. reported that CYP2J2 was expressed in the pancreatic islets, consistent with the finding that EETs, the metabolic products of AA, regulate the levels of insulin and glucagon (Zeldin et al., 1997). CYP2J2 and CYP2C9 enzymes are co-expressed in the pituitary gland, suggesting they can regulate the release of pituitary hormones including prolactin and growth hormone most likely via EETs (Snyder et al., 1989; Irusta et al., 2007).

In mammals, the CYP4 family primarily mediates the $\omega$-hydroxylation of PUFAs, which includes 12 genes and 13 enzymes, such as, CYP4A, CYP4B, CYP4F, CYP4V, CYP4X, and CYP4Z. CYP4A, CYP4B, CYP4X, and CYP4Z are located on chromosome 1, while CYP4F and CYP4V on chromosome 19 and 4, respectively (Nelson et al., 2004). The CYP4 is the largest one in the human CYP family, only a few of which mediate the $\omega$-hydroxylation of PUFAs (Simpson, 1997). In the CYP4 family, CYP4A11, CYP4F2, CYP4F3A, and CYP4F3B are the most studied. CYP4A11 has been reported to express primarily in the liver and kidney, which can be regulated by peroxisome proliferator-activated receptor- $\alpha$ (PPAR $\alpha$ ) and catalyze the metabolism of AA and lauric acid. CYP4F2 is also mainly expressed in the liver and kidney, and it is regulated by the sterol regulatory element-binding protein (SREBP). The P450 gene CYP4F3 is unusual, and CYP4F3A and CYP4F3B are two different spliceosomes. CYP4F3A is expressed in neutrophils and CYP4F3B is primarily expressed in the human liver and kidney. They are both the main $\omega$-hydroxylases of long-chain PUFAs. In addition, CYP4F8, CYP4F22, and CYP4V2 have been found to express predominantly in extrahepatic tissues. Among these enzymes, only CYP4V2 exhibits fatty acid $\omega$-hydroxylase activity. CYP4X1 and CYP4Z1 are both extrahepatic CYPs, the 
former is highly expressed in the brain, skin, and airways, and is inducible by glucocorticoids and progesterone.

Other CYPs, such as CYP1A1, CYP 1A2, CYP1B1, CYP2D6, and CYP3A4, can detoxificate carcinogens regardless of whether they are expressed in the liver or kidney.

In addition to many studies investigating the expression of CYP epoxygenases in multiple organ tissues, a few studies summarized the expression of CYP epoxygenases in some specific cell types. Almost all the CYP epoxygenases were found in peripheral blood cells, vascular endothelial cells, and vascular smooth muscle cells (Xu et al., 2013; Sausville et al., 2019). In addition, CYP2J was reported to express in many cells, including but not limited to LS-174, ScaBER, SiHa, U251, A549, Tca-8113, Ncl-H446, HepG2, K562, HL-60, MOLT-4, Jurkat, Raji, autonomic ganglion nerves, and smooth muscle cells, pancreatic islet cells, Purkinje cells (DeLozier et al., 2007; Xu et al., 2013; Sausville et al., 2019).

\section{The Association of Polymorphisms of Cytochrome P450s With Cancers}

Recently, the expression of various CYP genes has been proved to be closely related to malignant tumors. Polymorphisms of CYPs have been suggested to influence susceptibility to cancers for many years. Genetic polymorphisms in CYPs have been reported to be associated with individuals variations in drug metabolism and disease susceptibility (Pikuleva and Waterman, 2013; Mittal et al., 2015). Here, we discuss some important polymorphisms of CYPs in cancers (Table 1).

\section{CYP1A1}

CYP1A1 is a hepatic and extrahepatic enzyme that is regulated by the aryl hydrocarbon receptor signaling pathway. It has been always associated with the metabolism of pro-carcinogenic compounds to highly carcinogenic metabolites. For CYP1A1, four common variants (T3801C, A2455G, T3205C, and C2453A) were widely studied for the susceptibility to various cancers (Bozina et al., 2009). T3801C (rs4646903) and T3205C are situated in the $3^{\prime}$ noncoding region while A2455G (rs1048943) and $\mathrm{C} 2453 \mathrm{~A}$ are ascertained in exon 7 , which results in the transition of isoleucine to valine on codon 462 and threonine to asparagine on codon 461, respectively ( $\mathrm{Li}$ et al., 2004). The monomorphism of T3205C locus was reported in Indians (Singh et al., 2007), Americans (San Francisco) (Hirata et al., 2008), and Northeast Thai women (Wongpratate et al., 2020). Among several populations, the polymorphisms of T3801C and/ or A2455G were reported to associate significantly with the increased risk in cervical cancer (Juarez-Cedillo et al., 2007; Li et al., 2016; Jain et al., 2017; Wang et al., 2017; Ding et al., 2018). An association of T3801C (CC) genotype with increased cervical cancer risk was reported among the Asians population by a metaanalysis study (Wu et al., 2013). However, there is a lack of significant association between T3801C and A2455G polymorphisms and cervical cancer risk in Chinese, Japanese, Israeli Jewish, Polish, Indian, and Thai populations (Sugawara et al., 2003; Gutman et al., 2009; Roszak et al., 2014; Tan et al., 2016; Wongpratate et al., 2020). The A allele of C2453A is associated with the risk of lung cancer (Gallegos-Arreola et al., 2008; Ezzeldin et al., 2017), laryngeal squamous cell carcinoma (Gajecka et al., 2005), thyroid cancer (Siraj et al., 2008), and cervical cancer (Wongpratate et al., 2020), but not associated with breast (Li et al., 2004; Singh et al., 2007; Amrani et al., 2016), colorectal (Little et al., 2006), or gastric cancer (Agudo et al., 2006).

\section{CYP1A2}

CYP1A2, which is similar to CYP1A1, can metabolize a broad range of foreign compounds and drugs. An SNP C>A (rs762551) was found in intron one of CYP1A2 (Womack et al., 2012), which influences the inducibility of CYP1A2 (Koonrungsesomboon et al., 2018). The highest CYP1A2 induction rate was reported in AA genotype (Sachse et al., 1999), and the high enzyme activity carriers were at high risk of lung cancer (Seow et al., 2001; Bu et al., 2014). On the other hand, the low activity or downregulation of CYP1A2 influenced by the SNP would result in the progression of hepatocellular carcinoma (HCC). As the substrate of CYP1A2, 17 -estradiol can be metabolized to 2-hydroxyestradiol which is then converted to 2methoxyestradiol that inhibits HCC cells proliferation by inducing apoptosis (Ren et al., 2016). More recently, the CYP1A2 SNP rs762551 was found to be significantly associated with the high risk in breast cancer in the Jordanian population (Al-Eitan et al., 2019).

\section{CYP1B1}

CYP1B1 not only mediates the metabolisms of xenobiotics, e.g. theophylline, ethoxyresorufin, and caffeine (Rochat et al., 2001; Zanger and Schwab, 2013) but also activates some procarcinogens, such as aromatic amines, heterocyclic amines, nitropolycyclic and polycyclic hydrocarbons (Chun and Kim, 2016). CYP1B1 mutations were a causative factor of diseases. For example, L432V and A119S (rs1056827) polymorphisms of the CYP1B1 gene were reported to increase the risk of developing endometrial cancer (Zhu et al., 2011) and laryngeal cancers (Yu et al., 2015).

\section{CYP2A6}

CYP2A6 is an essential hepatic enzyme involved in the metabolism of drugs, is responsible for a major metabolic pathway of nicotine. The first polymorphism identified of CYP2A6 was a nonsynonymous polymorphism (L160H) (rs1801272) which leads to no enzyme activity (FernandezSalguero et al., 1995). There are more than 30 nonsynonymous polymorphisms in nine exons (Di et al., 2009). Some polymorphisms were found to be associated with smoking behavior, drug metabolism, and lung cancer risk (Di et al., 2009). The wild type CYP $2 \mathrm{~A} 6^{*} 1 \mathrm{~A}$ is with normal enzyme activity, and the CYP2A $6^{\star} 4$, including CYP2A $6^{\star} 4 \mathrm{~A}, \mathrm{CYP} 2 \mathrm{~A} 6^{\star} 4 \mathrm{~B}$, and CYP2A $6^{\star} 4 \mathrm{D}$, have no enzyme activity (Hukkanen et al., 2005). The CYP $2 A 6^{\star} 5$ encoded an unstable enzyme activity since the substitution of Glycin- 479 by valine occurred (Oscarson et al., 1999). CYP2A6 can activate procarcinogens, for instance, nitrosamines and aflatoxins. The absence of the CYP2A6 enzyme could reduce the risk of lung cancer because the 
activation of procarcinogens would be decreased. Therefore, the phenotypes of CYP $2 \mathrm{~A}^{\star} 4$ and CYP2A $6^{\star} 5$ protect the carriers against lung cancer or other cancers (Raunio et al., 2001).

\section{CYP2C9}

CYP2C9 metabolizes about $15 \%$ of clinically administrated drugs. Two common non-synonymous polymorphisms of CYP2C9, R144C, rs1799853 (CYP2C9*2), and I359L, rs1057910 (CYP2C9*3), have been reported to be highly frequent in Caucasian populations (Sistonen et al., 2009; Van Booven et al., 2010). These two polymorphisms result in poor metabolic activity of CYP2C9 (Van Booven et al., 2010), and are positively associated with the risk of cancer. Individuals with CYP2C9² (R144C, rs1799853) polymorphism have a severalfold increased risk of head and neck squamous cell carcinoma (HNSSC) (Yadav et al., 2014). On the contrary, as the CYP2C9 (R144C, rs1799853, and I359L, rs1057910) variants metabolize AA less efficiently than CYP2C9 wild type, they were proved to retard the development of non-small cell lung cancer (NSCLC) due to the reduced ability to generate EETs (Sausville et al., 2018). Recently, the relationship of CYP2C9 polymorphism with colorectal cancer (CRC) susceptibility was investigated by a number of case-control studies. But the results were controversary. A meta-analysis of 13 studies involving a total of 20,879 subjects for CYP2C9 (R144C, rs1799853 and I359L, rs1057910) polymorphisms to evaluate the effect of CYP2C9 on genetic susceptibility for CRC suggest that the CYP2C9 (R144C, rs1799853 and I359L, rs1057910) polymorphisms are not associated with CRC susceptibility (Zhao et al., 2013). Also, the CYP2C9 (R144C, rs1799853, and I359L, rs1057910) polymorphisms are not associated with lung cancer risk among African-Americans and Caucasians in Los Angeles (Zhao et al., 2013) or in white Spanish (Garcia-Martin et al., 2002).

\section{CYP2C19}

Among the CYP2C subfamily, CYP2C19 is the most polymorphic (Lee, 2012). CYP2C19 polymorphism leads to differences in enzyme expression and metabolic activity between individuals. CYP2C19 polymorphisms classified the population to poor, extensive, and ultra-rapid metabolic activity (Reynald et al., 2012). The two primary point mutation sites of CYP2C19 are CYP2C19*2 and CYP2C19*3, which cause poor metabolizer phenotype of CYP2C19. CYP2C19 polymorphisms have been analyzed about the prostate, bladder, lung, liver, colorectal cancer, and other cancers. No association of the CYP2C19*2 allele and prostate cancer was identified in the Swedish and Danish population (Wadelius et al., 1999). But there is a weak association between the CYP2C19*2 allele and bladder cancer (Brockmoller et al., 1996). Yan et al. found that there was a significant interaction between CYP2C19*3 and smoking in increasing the risk of lung cancer in a Chinese population (Yan et al., 2014). Similar results were reported in the Japanese population (Tsuneoka et al., 1996). CYP2C19*3 was identified to be associated with breast cancer risk in women (Gan et al., 2011). In contrast, a decreased breast cancer risk for carriers of the CYP2C19*17 allele was observed in German women
(Justenhoven et al., 2009), and a meta-analysis has found that $\mathrm{CYP} 2 \mathrm{C} 19^{\star} 2$ and $\mathrm{CYP} 2 \mathrm{C} 19^{*} 17$ genotypes are associated with increased survival of breast cancer patients treated with tamoxifen (Bai et al., 2014). Zhou et al. found that CYP2C19*2 causes a poor metabolizer phenotype, while $\mathrm{CYP} 2 \mathrm{C} 19^{\star} 3$ is associated with the increased risk of digestive system cancer, especially in East Asians (Zhou et al., 2013). Moreover, poor metabolizer genotypes were found to be associated with the increased risks in many cancers, such as esophagus cancer, gastric cancer, lung cancer, head neck cancer, and hepatocellular carcinoma, suggesting the CYP2C19² and CYP2C19*3 most likely contributes to cancer susceptibility, particularly in the Asian populations (Wang et al., 2013).

\section{CYP2D6}

CYP2D6 is one of the most studied enzymes in the field of pharmacogenetics. It exhibits large interindividual variability on drug metabolism. The polymorphism of CYP2D6 causes different metabolizer genotypes, including poor, intermediate, efficient, or ultra-rapid ones (Ingelman-Sundberg, 2005). The number of CYP2D6 polymorphisms is over seventy-five, and the association between CYP2D6 polymorphisms and cancer risk has been studied for many years (Agundez, 2004). Over twenty years ago, London et al. reported that the presence of inactivating CYP2D6 alleles (CYP2D6*4, CYP2D6*3, CYP2D6*5, and CYP2D6*16) may decrease the risk of lung cancer among the African-Americans, suggesting the CYP2D6 genetic polymorphism is not the strong risk factor for lung cancer but may play a minor role (London et al., 1997). By a meta-analysis, a minor but statistically significant association of CYP2D6 polymorphism with lung cancer susceptibility was established (Rostami-Hodjegan et al., 1998). Recently, associations between childhood acute leukemia (CAL) and genetic polymorphism of CYP2D6*4 for homozygous alleles were reported, suggesting CYP2D6*4 polymorphism could play a vital role in the etiology of CAL (Ferri et al., 2018). The association of Liver cancer with CYP2D6 genotype was also established by Agundez et al. (Agundez et al., 1995) In the HCC patients, the CYP2D6*10 allelic frequency was significantly different from those of control subjects. CYP2D6* 10 is also suggested to be a potential biomarker for hepatocarcinogenesis risk (Zhou et al., 2016). The role of CYP2D6 polymorphism in melanoma has been investigated by different research groups with consistent results, indicating individuals with defect genes are at increased risk (Wolf et al., 1992; Dolzan et al., 1995; Strange et al., 1999). In other cancers, CYP2D6 polymorphisms were demonstrated to be associated with prostate (Wadelius et al., 1999; Sobti et al., 2006), bladder (Abdel-Rahman et al., 1997; Ouerhani et al., 2008) and renal cancers (Ahmad et al., 2013).

\section{CYP3A4}

CYP3A4 is the best-studied gene polymorphism in the CYP3A family. A meta-analysis comprising 55 separate studies including 22,072 cancer cases and 25,433 controls found a significant association between CYP3A $4^{\star} 1 \mathrm{~B}$ and cancer risk especially leukemia in the overall population (Zheng et al., 2018). In the Chinese Han population, a relationship between the TT genotype 
of CYP3A $4^{\star} 1 \mathrm{G}$ (rs2242480) polymorphism and the risk of breast cancer was established (Liu et al., 2019). He et al. found that CYP3A4 A392G polymorphism, but not CYP3A5 Met235Thr, is associated with the increased risk in prostate cancer among Caucasians (He et al., 2014). Although there are many studies on CYP3A4 gene polymorphism and cancer susceptibility, the underlying mechanism is still unclear and needs to be further investigated.

\section{THE FUNCTION OF CYTOCHROME P450-MEDIATED EICOSANOIDS IN CANCERS}

\section{The Roles of Epoxyeicosatrienoic Acids in Cancer}

EETs were discovered in the early 1980s (Capdevila et al., 1981a; Capdevila et al., 1981b; Chacos et al., 1982). EETs have been found to function as the regulators of cardiac, vascular (Fleming, 2007; Fleming, 2008; Fleming, 2011; Fleming, 2016), and renal physiology (Imig, 2005; Capdevila and Wang, 2013; Capdevila et al., 2015), indicating many important roles on the homeostasis of healthy tissues. Nakagawa et al. reported that the loss of EETs is associated with hypertension (Nakagawa et al., 2006). More recently, EETs have also been found to be associated with tumorigenesis, cancer metastasis, and angiogenesis (Jiang et al., 2005; Jiang et al., 2007; Pozzi et al., 2007; Pozzi and Capdevila, 2008; Yang et al., 2009; Mitra et al., 2011; Panigrahy et al., 2012), recovery of cardiac tissue from ischemic insult (Seubert et al., 2007) and other pathophysiologic processes.

CYP-mediated biosynthesis of four EETs [5(6)-, 8(9)-, 11(12)-, and 14(15)-EET] has been implicated in tumor growth and angiogenesis, as well as suppression of inflammation in murine models of cancers (Panigrahy et al., 2011). Compared to adjacent normal tissue, human breast cancer tissue has a higher level of 14 (15)-EET, which was due to increased CYP2C8, CYP2C9, and
CYP2J2 and decreased sEH (Wei et al., 2014). Overexpression of CYP2J2 was found to be overexpressed in human neoplastic tissue and human cell lines when compared with the adjacent normal tissue and normal cell lines, respectively (Jiang et al., 2005; Jiang et al., 2007). CYP2C9 was found to express in the vasculature of several human tumor samples and be the regulatory target of human peroxisomal proliferator-activated receptor-alpha (PPARa), which have anti-angiogenic and anti-tumorigenic properties (Pozzi et al., 2010). The elevated EET levels by CYP overexpression or directly provided by the pump showed the ability to promote cancer metastasis in a murine model of cancer (Panigrahy et al., 2012). 14 (15)-EET has been exhibited to promote the proliferation of vascular endothelial cells (Cheranov et al., 2008) and estrogen receptor-positive breast cancer epithelial cells (Mitra et al., 2011). The molecular mechanism underlying the function of EETs on cancer cell proliferation is partly through activation of the $\mathrm{PI}_{3^{-}}$ kinase/AKT pathway and the $\mathrm{STAT}_{3}$ pathway (Jiang et al., 2005). More recently, Guo et al. discovered the mechanisms by which cancer cell-intrinsic CYP monooxygenases promote tumor progression are associated with breast cancer mitochondria and EETs promoted the electron transport chain/respiration and inhibited AMPKa (Guo et al., 2017). In triple-negative breast cancer (TNBC), EETs are important metastasis drivers. EET concentrations are associated with the upregulation of CYP2C19 and CYP2J2 (Apaya et al., 2019). In addition, EETs promote epithelial-mesenchymal transition (EMT) and resistance via the STAT and AKT signaling pathways (Zhang et al., 2006; Jiang et al., 2007; Mitra et al., 2011; Wei et al., 2014; Luo et al., 2018).

EETs are also anti-inflammatory (Node et al., 1999), which makes the biological action of EETs on cancer more complicated. In the murine model, 11(12)-EET can decrease the adhesion of mononuclear to vascular endothelium induced by tumor necrosis factor- $\alpha$ (TNF- $\alpha$ ) (Node et al., 1999). 14 (15)-EET can also inhibit the expression of TNF- $\alpha$ and IL- $1 \beta$ induced by LPS in mouse macrophages (Zhang et al., 2013b). These results supported that EETs are anti-inflammatory in human and mouse tissues.
A

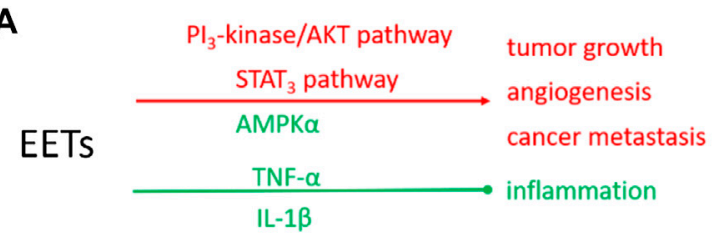

B

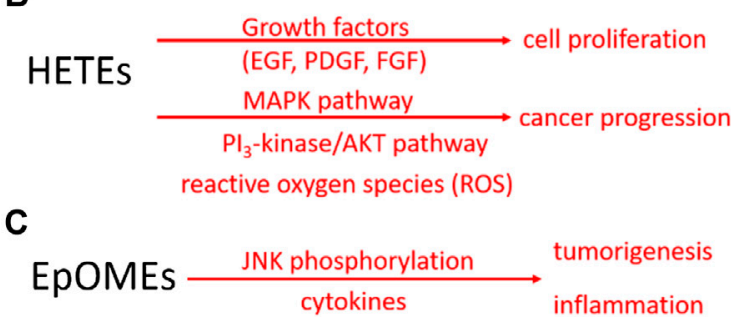

D

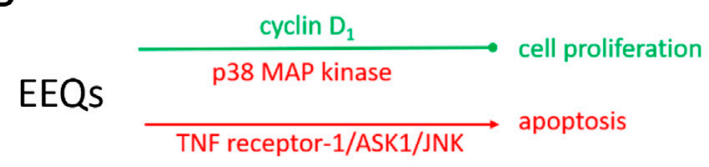

E

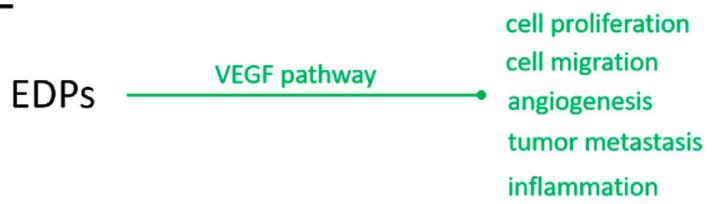

FIGURE 2 | Schematic diagram of molecular mechanisms of eicosanoids on the biological function of tumors. Red: indicating the enhanced signaling pathway or biological function; Green: indicating the suppressed signaling pathway or biological function solid line: proven pathways. The molecular mechanisms of EETs (A), HETEs (B), EpOMEs (C), EEQs (D), and EDPs (E). 
However, whether and how EETs play an anti-inflammatory role in cancer cells needs to be further investigated. The possible mechanisms underlying EETs regulate cancers are summarized in Figure 2A.

Recently, EETs were discovered to act the biological function in a receptor-dependent manner. However, the receptors of EETs have not been identified. Some research suggested that the actions of EETs are in part mediated via G protein-coupled receptor (GPCR) signaling. Five $G$ protein-coupled receptors of the prostaglandin receptor family (PTGER2, PTGER4, PTGFR, PTGDR, and PTGER3IV) may be the EET receptors (Liu et al., 2017).

\section{The Roles of Hydroxyeicosatetraenoic} Acids in Cancer

The studies of the role of HETEs in cancer focus on 20-HETE. 20HETE formed by CYP4 enzymes exhibits the proinflammatory function (Khanapure et al., 2007). In recent years, more attention has been paid to the promoting role of 20-HETE in cancer progression (Panigrahy et al., 2010; Alexanian and Sorokin, 2013). The endogenous 20-HETE formation has been implicated in cell proliferation by growth factors, including epidermal growth factor (EGF), platelet-derived growth factor

\begin{tabular}{|c|c|c|c|c|}
\hline CYPs & Polymorphism & Cancers & population & References \\
\hline \multirow[t]{10}{*}{ CYP1A1 } & T3801C & Cervical cancer & Asians & Wu et al., 2013 \\
\hline & and/or & & Indians & Jain et al., 2017 \\
\hline & A2455G & & Mexican & Juarez-Cedillo et al., 2007 \\
\hline & (rs1048943) & & Chinese & Li et al., 2016 \\
\hline & - & Laryngeal squamous cell carcinoma & Caucasian & Gajecka et al., 2005 \\
\hline & & Thyroid cancer & Middle eastern & Siraj et al., 2008 \\
\hline & & Cervical cancer & Northeast Thai & Wongpratate et al., 2020 \\
\hline & T3205C & Breast cancer & Indians & Singh et al., 2007 \\
\hline & (rs1800031) & Endometrial cancer & Caucasian & Hirata et al., 2008 \\
\hline & - & Cervical cancer & Northeast Thai & Wongpratate et al., 2020 \\
\hline \multirow[t]{3}{*}{ CYP2A6 } & CYP2A6*4 & Lung cancer & Japanese & Raunio et al., 2001 \\
\hline & and & & Caucasian & \\
\hline & CYP2A6*5 & & - & \\
\hline \multirow[t]{2}{*}{ CYP2C9 } & rs1799853 & Head and neck squamous cell carcinoma & Indian & Yadav et al., 2014 \\
\hline & $\begin{array}{l}\text { rs1799853 } \\
\text { and } \\
\text { rs1057910 }\end{array}$ & Non-small cell lung cancer & Caucasians & Sausville et al., 2018 \\
\hline \multirow[t]{5}{*}{ CYP2C19 } & $\begin{array}{l}\text { CYP2C19*2 } \\
\text { (rs4244285) }\end{array}$ & Bladder cancer & German & Brockmoller et al., 1996 \\
\hline & $\mathrm{CYP} 2 \mathrm{C} 19^{*} 3$ & Lung cancer & Chinese & Yan et al., 2014 \\
\hline & - & & Japanese & Tsuneoka et al., 1996 \\
\hline & & Breast cancer & Chinese & Gan et al., 2011 \\
\hline & & Digestive system cancer & East Asians & Zhou et al., 2013 \\
\hline & & Malignant melanoma & British & Strange et al., 1999 \\
\hline & $\begin{array}{l}\text { CYP2D6*3 } \\
\text { and }\end{array}$ & Prostate cancer & Danish & Wadelius et al., 1999 \\
\hline & CYP2D6*4 & & & \\
\hline & $\begin{array}{l}\text { CYP2D6*10 } \\
\text { (rs10655852) }\end{array}$ & Hepatocellular carcinoma & Chinese & Zhou et al., 2016 \\
\hline \multirow[t]{3}{*}{ CYP3A4 } & CYP3A4*1B & Leukemia & Chinese & Zheng et al., 2018 \\
\hline & $\begin{array}{l}\text { CYP3A4*1G } \\
\text { (rs2242480) }\end{array}$ & Breast cancer & Chinese & Liu et al., 2019 \\
\hline & CYP3A4 A392G & Prostate cancer & Caucasians & He et al., 2014 \\
\hline
\end{tabular}


(PDGF), and fibroblast growth factor (FGF). Guo et al. found CYP4/20-HETE pathway could influence the tumor volume. When implantation of glioma cells transfected with CYP4A1 into the rat, the tumor volume is a 10 -fold increase compared with normal cells (Guo et al., 2008). In NSCLC cells, CYP4A/20HETE increased the tumor growth rate and metastasis (Yu et al., 2011). The signaling mechanisms in CYP4/20-HETE induced cancer progression are mainly about the activation of MAPK pathway (Muthalif et al., 1998), $\mathrm{PI}_{3}$ K/Akt (Yu et al., 2011), and reactive oxygen species (ROS) (Guo et al., 2007), which was summarized as Figure 2B.

\section{The Roles of Epoxyoctadecenoic Acids in Cancer}

EpOMEs are the major epoxygenated fatty acids in human plasma produced from LA. EpOMEs, also called leukotoxins, have been shown to act as a responsible factor in circulatory shock, burn, pulmonary edema, and inflammation (Hanaki et al., 1991; Hayakawa et al., 1990; Kosaka et al., 1994; Ozawa et al., 1988; Totani et al., 2000). EpOMEs are pro-inflammatory in severe burn patients (Totani et al., 2000; Zheng et al., 2001). Recently, EpOMEs are found to have pro-cancer activity in a murine model of colorectal cancer (Wang et al., 2019). Evidence indicated that high LA diets increased the azoxymethane-induced colon tumorigenesis in rat models (Zheng et al., 2001; Wu et al., 2004; Fujise et al., 2007; Enos et al., 2016). Case-control studies showed opposing associations of serum n-3 and n-6 PUFAs with the risk of colorectal adenoma (Pot et al., 2008). Researchers found treatment with 12(13)-EpOME increased cytokine production and JNK phosphorylation in vitro and exacerbated azoxymethane (AOM)/dextran sodium sulfate (DSS)-induced colon tumorigenesis in vivo (Wang et al., 2019). The underlying molecular mechanisms involved in the regulatory role of EpOMEs on cancer progression are not fully understood, partly because the specific receptors or direct cellular targets of EpOMEs are unknown. The effects of EpOMEs on cancers were summarized as Figure 2C. EpOMEs could be further metabolized to form DiHOMEs in the presence of sEH. Studies also showed DiHOMEs could induce chemotaxis, tissue injury, and cause mortality like EpOMEs in animal models (Moghaddam et al., 1997; Zheng et al., 2001).

\section{The Roles of Epoxyeicosatetraenoic Acid in Cancer}

Epidemiological studies revealed that dietary intake of EPA, the precursor of EEQs, decreases cancer risk (Bougnoux, 1999). Cui et al. have found that 17(18)-EEQ, but not 14(15)-, 11(12)-, 8(9)-, 5(6)-EEQ suppressed cell proliferation by down-regulating cyclin $\mathrm{D}_{1}$ and activation of growth-suppressing p38 MAP kinase (Cui et al., 2011). Another research also revealed that a novel synthetic analog of 17(18)-EEQ activated TNF receptor-1/ASK1/JNK signaling to promote apoptosis in human breast cancer cells, manifesting the anticancer action of 17(18)-EEQ (Dyari et al., 2017). Up to now, the role of EEQ in cancer and its molecular mechanism has not been fully studied, which needs to be further studied in the future. The putative mechanism underlying EEQ in cancer was summarized as Figure 2D.

\section{The Roles of Epoxydocosapentaenoic Acids in Cancer}

EDPs are the metabolites of DHA mediated by CYP enzymes. They are suggested to be responsible for some of the beneficial effects of n-3 PUFAs and n-3 PUFA-rich diet (Arnold et al., 2010). Evidence has shown that the metabolites of n-3 PUFAs, mainly EDPs, mediate some effects in chronic disease conditions, such as hypertension, pain, and kidney diseases (Ulu et al., 2014; Deng et al., 2017; Hasegawa et al., 2017). More recently, some experimental studies showed that 16(17)- and 19(20)-EDPs are important mediators in suppressing inflammation and inhibiting angiogenesis, endothelial cell migration, endothelial cell proliferation, and tumor metastasis (Zhang et al., 2013a; Yanai et al., 2014; Hasegawa et al., 2017). EDPs are super unstable in vivo since they could be rapidly metabolized by $\mathrm{sEH}$ to form corresponding diols. Zhang et al. found 19,20dihydroxydocosapentaenoic acid (19,20-DiHDPA), the metabolite of 19 (20)-EDP mediated by $\mathrm{sEH}$, did not have any effect on tumor growth, indicating that the anticancer effect was from 19 (20)-EDP but not its diol metabolite (Zhang et al., 2013a). The putative mechanism of EDPs in cancer was summarized as Figure 2E.

\section{CONCLUSION}

Increasing studies supported the important role of CYPderived eicosanoids in the progression of cancer and the resolution of inflammation. The action of EETs and EpOMEs has been investigated for decades while EEQs and EDPs are less-studied. Further studies are suggested to pay more attention to EEQs and EDPs since increasing the supplement of EPA and DHA with a focus on the biological activities of these eicosanoids and underlying mechanisms.

The additional complexity of the regulation of eicosanoids on inflammation, pain, angiogenesis, and cancer is the $\mathrm{sEH}$ enzyme, which can rapidly metabolize many CYPs-derived eicosanoids to corresponding fatty acid diols (Chacos et al., 1983; Zeldin et al., 1995; Zhang et al., 2014a). sEHs may modulate tumor angiogenesis by hydrolyzing proangiogenic EETs (Panigrahy et al., 2012). sEH also can hydrolyze anti-angiogenic epoxides of DHA (Zhang et al., 2013a). Co-inhibition of sEH resulted in a synergistic antiinflammatory effect of the inhibitors of COXs and LOXs (Schmelzer et al., 2006; Liu et al., 2010; Hwang et al., 2011). Zhang et al. reported the anti-cancer effects of a dual inhibitor of sEH and COX (Zhang et al., 2014b). In short, the roles of CYPs/epoxides/sEH axis in cancer progression is substrate-dependent. Generally speaking, the CYP-mediated eicosanoids derived from $\omega-6$ fatty acids (e.g. LA and AA) exacerbate cancer while the ones from $\omega$-3 fatty acids (e.g. 
EPA and DHA) are beneficial in the prevention and/or treatment of cancer. Manipulation of the CYPs/sEH pathway with or without supplement of $\omega-3$ fatty acids to regulate target eicosanoids levels may be a promising strategy to prevent and/or treat cancers.

\section{REFERENCES}

Abdel-Rahman, S. Z., Anwar, W. A., Abdel-Aal, W. E., Ghoneim, M. A., and Au, W. W. (1997). The CYP2D6 extensive metabolizer genotype is associated with increased risk for bladder cancer. Cancer Lett. 119, 115-122. doi:10.1016/s03043835(97)00265-6

Agudo, A., Sala, N., Pera, G., Capella, G., Berenguer, A., Garcia, N., et al. (2006). Polymorphisms in metabolic genes related to tobacco smoke and the risk of gastric cancer in the European prospective investigation into cancer and nutrition. Cancer Epidemiol. Biomark. Prev. 15, 2427-2434. doi:10.1158/ 1055-9965.epi-06-0072

Agundez, J. A. (2004) Cytochrome P450 gene polymorphism and cancer. Curr. Drug Metabol. 5, 211-224. doi:10.2174/1389200043335621

Agúndez, J. A. G., Leedesma, M. C., Benítez, J., Ladero, J. M., Rodríguez-Lescure, A., Díaz-Rubio, E., et al. (1995). CYP2D6 genes and risk of liver cancer. Lancet 345, 830-831. doi:10.1016/s0140-6736(95)92965-7

Ahmad, S. T., Arjumand, W., Seth, A., Nafees, S., Rashid, S., Ali, N., et al. (2013). Risk of renal cell carcinoma and polymorphism in phase I xenobiotic metabolizing CYP1A1 and CYP2D6 enzymes. Urol. Oncol.: Semin. Orig. Invest. 31, 1350-1357. doi:10.1016/j.urolonc.2011.12.009

Al-Eitan, L. N., Rababa’h, D. M., Alghamdi, M. A., and Khasawneh, R. H. (2019). Association of CYP gene polymorphisms with breast cancer risk and prognostic factors in the Jordanian population. BMC Med. Genet. 20, 148. doi:10.1186/ s12881-019-0884-x

Alexanian, A. and Sorokin, A. (2013). Targeting 20-HETE producing enzymes in cancer-rationale, pharmacology, and clinical potential. OncoTargets Ther. 6, 243-255. doi:10.2147/OTT.S31586

Amrani, I., Bulatova, N., Awidi, A., Yousef, A.-M., Melhem, J. M., Al-Masri, M., et al. (2019). Lack of association between CYP1A1 M2 and M4 polymorphisms and breast carcinoma in Jordanian women: a case-control study. Asian Pac. J. Cancer Prev. APJCP 17, 387-393. doi:10.7314/apjcp.2016.17.1.387

Apaya, M. K., Shiau, J. Y., Liao, G. S., Liang, Y. J., Chen, C. W., Yang, H. C., et al. (2019). Integrated omics-based pathway analyses uncover CYP epoxygenaseassociated networks as theranostic targets for metastatic triple negative breast cancer. J. Exp. Clin. Canc. Res. 38, 187. doi:10.1186/s13046-019-1187-y

Arnold, C., Markovic, M., Blossey, K., Wallukat, G., Fischer, R., Dechend, R., et al. (2010). Arachidonic acid-metabolizing cytochrome P450 enzymes are targets of $\omega-3$ fatty acids. J. Biol. Chem. 285, 32720-32733. doi:10.1074/jbc.m110. 118406

Bai, L., He, J., He, G.-H., He, J.-C., Xu, F., and Xu, G.-L. (2014). Association of CYP2C19 polymorphisms with survival of breast cancer patients using tamoxifen: results of a meta-analysis. Asian Pac. J. Cancer Prev. APJCP 15, 8331-8335. doi:10.7314/apjcp.2014.15.19.8331

Bougnoux, P. (1999). n-3 polyunsaturated fatty acids and cancer. Curr. Opin. Clin. Nutr. Metab. Care 2, 121-126. doi:10.1097/00075197-199903000-00005

Bozina, N., Bradamante, V., and Lovrić, M. (2009). Genetic polymorphism of metabolic enzymes P450 (CYP) as a susceptibility factor for drug response, toxicity, and cancer risk. Arh. Hig. Rada. Toksikol. 60, 217-242. doi:10.2478/ 10004-1254-60-2009-1885

Brockmöller, J., Cascorbi, I., Kerb, R., and Roots, I. (1996). Combined analysis of inherited polymorphisms in arylamine $\mathrm{N}$-acetyltransferase 2, glutathione S-transferases M1 and T1, microsomal epoxide hydrolase, and cytochrome P450 enzymes as modulators of bladder cancer risk. Cancer Res 56, 3915-3925

Bu, Z.-B., Ye, M., Cheng, Y., and Wu, W.-Z. (2014). Four polymorphisms in the cytochrome P450 1A2 (CYP1A2) gene and lung cancer risk: a meta-analysis. Asian Pac. J. Cancer Prev. APJCP 15, 5673-5679. doi:10.7314/apjcp.2014.15.14. 5673

Capdevila, J., Chacos, N., Werringloer, J., Prough, R. A., and Estabrook, R. W. (1981a). Liver microsomal cytochrome P-450 and the oxidative metabolism of

\section{AUTHOR CONTRIBUTIONS}

YL and JYL designed the paper frame; YL wrote the draft; JYL critically revised and finalized the paper. YL and JYL approved the final version.

arachidonic acid. Proc. Natl. Acad. Sci. U.S.A. 78, 5362-5366. doi:10.1073/pnas. 78.9 .5362

Capdevila, J. H., Wang, W., and Falck, J. R. (2015). Arachidonic acid monooxygenase: genetic and biochemical approaches to physiological/ pathophysiological relevance. Prostag. Other Lipid Mediat. 120, 40-49. doi:10.1016/j.prostaglandins.2015.05.004

Capdevila, J., Parkhill, L., Chacos, N., Okita, R., Masters, B. S. S., and Estabrook, R. W. (1981b). The oxidative metabolism of arachidonic acid by purified cytochromes P-450. Biochem. Biophys. Res. Commun. 101, 1357-1363. doi:10.1016/0006-291x(81)91597-7

Capdevila, J., and Wang, W. (2013). Role of cytochrome P450 epoxygenase in regulating renal membrane transport and hypertension. Curr. Opin. Nephrol. Hypertens. 22, 163-169. doi:10.1097/mnh.0b013e32835d911e

Cathcart, M.-C., O’Byrne, K. J., Reynolds, J. V., O’Sullivan, J., and Pidgeon, G. P. (2012). COX-derived prostanoid pathways in gastrointestinal cancer development and progression: novel targets for prevention and intervention. Biochim. Biophys. Acta Rev. Cancer 1825, 49-63. doi:10.1016/j.bbcan.2011.09. 004

Chacos, N., Capdevila, J., Falck, J. R., Manna, S., Martin-Wixtrom, C., Gill, S. S., et al. (1983). The reaction of arachidonic acid epoxides (epoxyeicosatrienoic acids) with a cytosolic epoxide hydrolase. Arch. Biochem. Biophys. 223, 639-648. doi:10.1016/0003-9861(83)90628-8

Chacos, N., Falck, J. R., Wixtrom, C., and Capdevila, J. (1982). Novel epoxides formed during the liver cytochrome P-450 oxidation of arachidonic acid. Biochem. Biophys. Res. Commun. 104, 916-922. doi:10.1016/0006-291x(82) 91336-5

Chang, G. W. M., and Kam, P. C. A. (1999). The physiological and pharmacological roles of cytochrome P450 isoenzymes. Anaesthesia 54, 42-50. doi:10.1046/j. 1365-2044.1999.00602.x

Cheranov, S. Y., Karpurapu, M., Wang, D., Zhang, B., Venema, R. C., and Rao, G. N. (2012). An essential role for SRC-activated STAT-3 in 14,15-EET-induced VEGF expression and angiogenesis. Blood 111, 5581-5591. doi:10.1182/blood2007-11-126680

Chuang, S. S., Helvig, C., Taimi, M., Ramshaw, H. A., Collop, A. H., Amad, M. A., et al. (2012). CYP2U1, a novel human thymus- and brain-specific cytochrome P450, catalyzes $\omega$ - and ( $\omega$-1)-Hydroxylation of fatty acids. J. Biol. Chem. 279, 6305-6314. doi:10.1074/jbc.m311830200

Chun, Y.-J., and Kim, D. (2016). Cancer activation and polymorphisms of human cytochrome P450 1B1. Toxicol. Res. 32, 89-93. doi:10.5487/tr.2016. 32.2.089

Cui, P. H., Petrovic, N., and Murray, M. (2011). The $\omega-3$ epoxide of eicosapentaenoic acid inhibits endothelial cell proliferation by 38 MAP kinase activation and cyclin D1/CDK4 down-regulation. Br. J. Pharmacol. 162, 1143-1155. doi:10.1111/j.1476-5381.2010.01113.x

DeLozier, T. C., Kissling, G. E., Coulter, S. J., Dai, D., Foley, J. F., Bradbury, J. A., et al. (2007). Detection of human CYP2C8, CYP2C9, and CYP2J2 in cardiovascular tissues. Drug Metab. Dispos. 35, 682-688. doi:10.1124/dmd. 106.012823

Deng, B.-Q., Luo, Y., Kang, X., Li, C.-B., Morisseau, C., Yang, J., et al. (2017). Epoxide metabolites of arachidonate and docosahexaenoate function conversely in acute kidney injury involved in GSK3 $\beta$ signaling. Proc. Natl. Acad. Sci. U.S.A. 114, 12608-12613. doi:10.1073/pnas.1705615114

Dennis, E. A. and Norris, P. C. (2015). Eicosanoid storm in infection and inflammation. Nat. Rev. Immunol. 15, 511-523. doi:10.1038/nri3859

Deremer, D. L., Ustun, C., and Natarajan, K. (2008). Nilotinib: a second-generation tyrosine kinase inhibitor for the treatment of chronic myelogenous leukemia. Clin. Therapeut. 30, 1956-1975. doi:10.1016/j.clinthera.2008.11.014

Di, Y., Chow, V., Yang, L.-P., and Zhou, S.-F. (2012). Structure, function, regulation and polymorphism of human cytochrome P450 2A6. Curr. Drug Metabol. 10, 754-780. doi:10.2174/138920009789895507. 
Ding, B., Sun, W., Han, S., Cai, Y., Ren, M., and Shen, Y. (2018). Cytochrome P450 $1 \mathrm{~A} 1$ gene polymorphisms and cervical cancer risk: a systematic review and meta-analysis. Medicine (Baltimore) 97, e0210. doi:10.1097/MD. 0000000000010210

Dolzan, V., Rudolf, Z., and Breskvar, K. (1995). Human CYP2D6 gene polymorphism in Slovene cancer patients and healthy controls. Carcinogenesis 16, 2675-2678. doi:10.1093/carcin/16.11.2675

Dyari, H. R. E., Rawling, T., Chen, Y., Sudarmana, W., Bourget, K., Dwyer, J. M., et al. (2017). A novel synthetic analogue of $\omega-3$ 17,18-epoxyeicosatetraenoic acid activates TNF receptor-1/ASK1/JNK signaling to promote apoptosis in human breast cancer cells. Faseb. J. 31, 5246-5257. doi:10.1096/fj.201700033r

Enos, R. T., Velázquez, K. T., McClellan, J. L., Cranford, T. L., Nagarkatti, M., and Nagarkatti, P. S. (2016). High-fat diets rich in saturated fat protect against azoxymethane/dextran sulfate sodium-induced colon cancer. Am. J. Physiol. Gastrointest. Liver Physiol. 310, G906-G919. doi:10.1152/ajpgi.00345.2015

Ezzeldin, N., El-Lebedy, D., Darwish, A., El-Bastawisy, A., Hassan, M., Abd ElAziz, S., et al. (2017). Genetic polymorphisms of human cytochrome P450 CYP1A1 in an Egyptian population and tobacco-induced lung cancer. Gene Environ. 39, 7. doi:10.1186/s41021-016-0066-4

Fernandez-Salguero, P., Hoffman, S. M., Cholerton, S., Mohrenweiser, H., Raunio, H., Rautio, A., et al. (1995). A genetic polymorphism in coumarin 7hydroxylation: sequence of the human CYP2A genes and identification of variant CYP2A6 alleles. Am. J. Hum. Genet. 57, 651-660. Pubmed

Ferri, G. M., Guastadisegno, C. M., Intranuovo, G., Cavone, D., Birtolo, F., and Cecinati, V. (2018). Maternal exposure to pesticides, paternal occupation in the army/police force, and CYP2D6 ${ }^{\star} 4$ polymorphism in the etiology of childhood acute leukemia. J. Pediatr. Hematol. Oncol. 40, e207-e214. doi:10.1097/mph. 0000000000001105

Fleming, I. (2007). Epoxyeicosatrienoic acids, cell signaling and angiogenesis. Prostag. Other Lipid Mediat. 82, 60-67. doi:10.1016/j.prostaglandins.2006.05. 003

Fleming, I. (2011). The cytochrome P450 pathway in angiogenesis and endothelial cell biology. Canc. Metastasis Rev. 30, 541-555. doi:10.1007/s10555-011-9302-3

Fleming, I. (2016). The factor in EDHF: cytochrome P450 derived lipid mediators and vascular signaling. Vasc. Pharmacol. 86: 31-40. doi:10.1016/j.vph.2016.03. 001

Fleming, I. (2008). Vascular cytochrome p450 enzymes: physiology and pathophysiology. Trends Cardiovasc. Med. 18, 20-25. doi:10.1016/j.tcm.2007. 11.002

Fujise, T., Iwakiri, R., Kakimoto, T., Shiraishi, R., Sakata, Y., Wu, B., et al. (2007). Long-term feeding of various fat diets modulates azoxymethane-induced colon carcinogenesis through $\mathrm{Wnt} / \beta$-catenin signaling in rats. $\mathrm{Am}$. J. Physiol. Gastrointest. Liver Physiol. 292, G1150-G1156. doi:10.1152/ ajpgi.00269.2006

Gajecka, M., Rydzanicz, M., Jaskula-Sztul, R., Kujawski, M., Szyfter, W., and Szyfter, K. (2005). CYP1A1, CYP2D6, CYP2E1, NAT2, GSTM1 and GSTT1 polymorphisms or their combinations are associated with the increased risk of the laryngeal squamous cell carcinoma. Mutat. Res. Fund Mol. Mech. Mutagen 574, 112-123. doi:10.1016/j.mrfmmm.2005.01.027

Gallegos-Arreola, M. P., Figuera-Villanueva, L. E., Troyo-Sanroman, R., MorgnVillela, G., Puebla-Prez, A. M., Flores-Marquez, M. R., et al. (2008). CYP1A1 ${ }^{*} 2 \mathrm{~B}$ and ${ }^{*} 4$ polymorphisms are associated with lung cancer susceptibility in Mexican patients. Int. J. Biol. Markers 23, 24-30. doi:10.1177/ 172460080802300104

Gan, C. Q., Wang, X. Y., Cao, Y. D., Ye, W. X., Liu, H., and Sun, Y. Y. (2011). Association of $\mathrm{CYP} 2 \mathrm{C} 19^{*} 3$ gene polymorphism with breast cancer in Chinese women. Genet. Mol. Res. 10, 3514-3519. doi:10.4238/2011.december.5.3

García-Martín, E., Martínez, C., Ladero, J. M., Gamito, F. J., Rodriguez-Lescure, A., and Agúndez, J. A. (2002). Influence of cytochrome P450 CYP2C9 genotypes in lung cancer risk. Canc. Lett. 180, 41-46. doi:10.1016/s0304-3835(02)00015-0

Guengerich, F. P. (2017). Intersection of the roles of cytochrome P450 enzymes with xenobiotic and endogenous substrates: relevance to toxicity and drug interactions. Chem. Res. Toxicol. 30, 2-12. doi:10.1021/acs.chemrestox. $6 \mathrm{~b} 00226$.

Guengerich, F. P. (2007). Mechanisms of cytochrome P450 substrate oxidation: MiniReview. J. Biochem. Mol. Toxicol. 21, 163-168. doi:10.1002/jbt.20174

Guo, A. M., Arbab, A. S., Falck, J. R., Chen, P., Edwards, P. A., Roman, R. J., and Scicli, A. G. (2007). Activation of vascular endothelial growth factor through reactive oxygen species mediates 20 -hydroxyeicosatetraenoic acid-induced endothelial cell proliferation. J. Pharmacol. Exp. Therapeut. 321, 18-27. doi:10.1124/jpet.106.115360

Guo, A. M., Sheng, J., Scicli, G. M., Arbab, A. S., Lehman, N. L., Edwards, P. A., et al. (2017). Expression of CYP4A1 in U251 human glioma cell induces hyperproliferative phenotype in vitro and rapidly growing tumors in vivo. J. Pharmacol. Exp. Therapeut. 327, 10-19. doi:10.1124/jpet.108.140889

Guo, Z., Sevrioukova, I. F., Denisov, I. G., Zhang, X., Chiu, T.-L., Thomas, D. G., et al. (2017). Heme binding biguanides target cytochrome P450-dependent cancer cell mitochondria. Cell Chem. Biol 24, 1314. doi:10.1016/j.chembiol. 2017.09.012

Gutman, G., Morad, T., Peleg, B., Peretz, C., Bar-Am, A., Safra, T., and Grisaru, D. (2009). CYP1A1 and CYP2D6 gene polymorphisms in Israeli Jewish women with cervical cancer. Int. J. Gynecol. Cancer 19, 1300-1302. doi:10.1111/igc. ob013e3181b9fa5d

Hanaki, Y., Kamiya, H., Ohno, M., Hayakawa, M., Sugiyama, S., and Ozawa, T. (1991). Leukotoxin, 9,10-epoxy-12-octadecenoate: a possible responsible factor in circulatory shock and disseminated intravascular coagulation. Jpn. J. Med. 30, 224-228. doi:10.2169/internalmedicine1962.30.224

Hasegawa, E., Inafuku, S., Mulki, L., Okunuki, Y., Yanai, R., Smith, K. E., et al. (2017). Cytochrome P450 monooxygenase lipid metabolites are significant second messengers in the resolution of choroidal neovascularization. Proc. Natl. Acad. Sci. U.S.A. 114, E7545-E7553. doi:10.1073/pnas.1620898114

Hayakawa, M., Kosaka, K., Sugiyama, S., Yokoo, K., Aoyama, H., Izawa, Y., and Ozawa, T. (1990). Proposal of leukotoxin, 9,10-epoxy-12-octadecenoate, as a burn toxin. Biochem. Int. 21, 573-579

He, X.-F., Liu, Z.-Z., Xie, J.-J., Wang, W., Du, Y.-P., Chen, Y., and Wei, W. (2014). Association between the CYP3A4 and CYP3A5 polymorphisms and cancer risk: a meta-analysis and meta-regression. Tumor Biol. 35, 9859-9877. doi:10. 1007/s13277-014-2241-1

Hirata, H., Hinoda, Y., Okayama, N., Suehiro, Y., Kawamoto, K., Kikuno, N., et al. (2008). CYP1A1, SULT1A1, andSULT1E1 polymorphisms are risk factors for endometrial cancer susceptibility. Cancer 112, 1964-1973. doi:10.1002/cncr. 23392

Hukkanen, J., Jacob, P., 3rd, and Benowitz, N. L. (2005). Metabolism and disposition kinetics of nicotine. Pharmacol. Rev. 57, 79-115. doi:10.1124/pr. 57.1.3

Hwang, S. H., Wagner, K. M., Morisseau, C., Liu, J.-Y., Dong, H., Wecksler, A. T., et al. (2011). Synthesis and Structure-Activity relationship studies of urea-containing pyrazoles as dual inhibitors of cyclooxygenase- 2 and soluble epoxide hydrolase. J. Med. Chem. 54, 3037-3050. doi:10.1021/ jm2001376

Imig, J. D. (2005). Epoxide hydrolase and epoxygenase metabolites as therapeutic targets for renal diseases. Am. J. Physiol. Ren. Physiol. 289, F496-F503. doi:10. 1152/ajprenal.00350.2004

Ingelman-Sundberg, M. (2005). Genetic polymorphisms of cytochrome P450 2D6 (CYP2D6): clinical consequences, evolutionary aspects and functional diversity. Pharmacogen. J. 5, 6-13. doi:10.1038/sj.tpj.6500285

Irusta, G., Murphy, M. J., Perez, W. D., and Hennebold, J. D. (2007). Dynamic expression of epoxyeicosatrienoic acid synthesizing and metabolizing enzymes in the primate corpus luteum. Mol. Hum. Reprod. 13, 541-548. doi:10.1093/ molehr/gam044

Jain, V., Ratre, Y. K., Amle, D., Mishra, P. K., and Patra, P. K. (2017). Polymorphism of CYP1A1 gene variants rs4646903 and rs1048943 relation to the incidence of cervical cancer in Chhattisgarh. Environ. Toxicol. Pharmacol. 52, 188-192. doi:10.1016/j.etap.2017.04.009

Jamieson, K. L., Endo, T., Darwesh, A. M., Samokhvalov, V., and Seubert, J. M. (2017). Cytochrome P450-derived eicosanoids and heart function. Pharmacol. Therap. 179, 47-83. doi:10.1016/j.pharmthera.2017.05.005

Jiang, J.-G., Chen, C.-L., Card, J. W., Yang, S., Chen, J.-X., Fu, X.-N., et al. (2005). Cytochrome P450 2J2 promotes the neoplastic phenotype of carcinoma cells and is up-regulated in human tumors. Cancer Res. 65, 4707-4715. doi:10.1158/ 0008-5472.can-04-4173

Jiang, J.-G., Ning, Y.-G., Chen, C., Ma, D., Liu, Z.-J., Yang, S., et al. (2007). CytochromeP450 epoxygenase promotes human cancer metastasis. Cancer Res. 67, 6665-6674. doi:10.1158/0008-5472.can-06-3643

Juárez-Cedillo, T., Vallejo, M., Fragoso, J. M., Hernández-Hernández, D. M., Rodríguez-Pérez, J. M., Sánchez-García, S., et al. (2007). The risk of 
developing cervical cancer in Mexican women is associated to CYP1A1 MspI polymorphism. Eur. J. Cancer 43, 1590-1595. doi:10.1016/j.ejca.2007.03.025

Justenhoven, C., Hamann, U., Pierl, C. B., Baisch, C., Harth, V., Rabstein, S., et al. (2009). CYP2C19*17 is associated with decreased breast cancer risk. Breast Canc. Res. Treat. 115, 391-396. doi:10.1007/s10549-008-0076-4

Khanapure, S., Garvey, D., Janero, D., and Gordon Letts, L. (2007). Eicosanoids in inflammation: biosynthesis, pharmacology, and therapeutic frontiers. Curr. Top. Med. Chem. 7, 311-340. doi:10.2174/156802607779941314

Knab, L. M., Grippo, P. J., and Bentrem, D. J. (2014). Involvement of eicosanoids in the pathogenesis of pancreatic cancer: the roles of cyclooxygenase-2 and 5lipoxygenase. World J. Gastroenterol. 20, 10729-10739. doi:10.3748/wjg.v20. i31.10729

Koonrungsesomboon, N., Khatsri, R., Wongchompoo, P., and Teekachunhatean, S. (2018). The impact of genetic polymorphisms on CYP1A2 activity in humans: a systematic review and meta-analysis. Pharmacogen. J. 18, 760-768. doi:10.1038/ s41397-017-0011-3

Kosaka, K., Suzuki, K., Hayakawa, M., Sugiyama, S., and Ozawa, T. (1994). Leukotoxin, a linoleate epoxide: its implication in the late death of patients with extensive burns. Mol. Cell. Biochem. 139, 141-148. doi:10.1007/bf01081737

Lee, S. J. (2012). Clinical application of CYP2C19 pharmacogenetics toward more personalized medicine. Front. Genet. 3, 318. doi:10.3389/fgene.2012.00318

Li, S., Li, G., Kong, F., Liu, Z., Li, N., Li, Y., and Guo, X. (2016). The association of CYP1A1 gene with cervical cancer and additional SNP-SNP interaction in Chinese women. J. Clin. Lab. Anal. 30, 1220-1225. doi:10.1002/jcla.22006

Li, Y., Millikan, R. C., Bell, D. A., Cui, L., Tse, C.-K. J., Newman, B., et al. (2004). Cigarette smoking, cytochrome $\mathrm{P} 4501 \mathrm{Al}$ polymorphisms, and breast cancer among African-American and white women. Breast Cancer Res. 6, R460-R473. doi:10.1186/bcr814

Little, J., Sharp, L., Masson, L. F., Brockton, N. T., Cotton, S. C., Haites, N. E., et al. (2006). Colorectal cancer and genetic polymorphisms ofCYP1A1,GSTM1andGSTT1: a case-control study in the Grampian region of Scotland. Int. J. Canc. 119, 2155-2164. doi:10.1002/ijc.22093

Liu, J.-Y., Yang, J., Inceoglu, B., Qiu, H., Ulu, A., Hwang, S.-H., Chiamvimonvat, N., and Hammock, B. D. (2010). Inhibition of soluble epoxide hydrolase enhances the anti-inflammatory effects of aspirin and 5-lipoxygenase activation protein inhibitor in a murine model. Biochem. Pharmacol. 79, 880-887. doi:10.1016/j. bcp.2009.10.025

Liu, X., Huang, X., Zhang, S., Niu, F., Ouyang, Y., Shou, Z., and Liu, J. (2019). Correlations between CYP3A4 polymorphism and susceptibility to breast cancer in Chinese Han population. Int. J. Clin. Oncol. 24, 179-188. doi:10. 1007/s10147-018-1346-8

Liu, X., Qian, Z.-Y., Xie, F., Fan, W., Nelson, J. W., Xiao, X., et al. (2017). Functional screening for $\mathrm{G}$ protein-coupled receptor targets of 14,15-epoxyeicosatrienoic acid. Prostag. Other Lipid Mediat. 132, 31-40. doi:10.1016/j.prostaglandins. 2016.09.002

London, S., Daly, A. K., Leathart, J. B., Navidi, W. C., Carpenter, C. C., and Idle, J. R. (1997). Genetic polymorphism of CYP2D6 and lung cancer risk in africanAmericans and Caucasians in Los Angeles county. Carcinogenesis 18, 1203-1214. doi:10.1093/carcin/18.6.1203

Luo, J., Yao, J. F., Deng, X. F., Zheng, X. D., Jia, M., Wang, Y. Q., et al. (2018). 14, 15-EET induces breast cancer cell EMT and cisplatin resistance by upregulating integrin alphavbeta3 and activating FAK/PI3K/AKT signaling. J. Exp. Clin. Canc. Res. 37, 23. doi:10.1186/s13046-018-0694-6

Mitra, R., Guo, Z., Milani, M., Mesaros, C., Rodriguez, M., Nguyen, J., et al. (2011). CYP3A4 mediates growth of estrogen receptor-positive breast cancer cells in part by inducing nuclear translocation of phospho-stat3 through biosynthesis of ( \pm )-14,15-Epoxyeicosatrienoic acid (EET). J. Biol. Chem. 286, 17543-17559. doi:10.1074/jbc.m110.198515

Mittal, B., Tulsyan, S., Kumar, S., Mittal, R. D., and Agarwal, G. (2015). Cytochrome P450 in cancer susceptibility and treatment. Adv. Clin. Chem. 71, 77-139. doi:10.1016/bs.acc.2015.06.003

Moghaddam, M. F., Grant, D. F., Cheek, J. M., Greene, J. F., Williamson, K. C., and Hammock, B. D. (1997). Bioactivation of leukotoxins to their toxic diols by epoxide hydrolase. Nat. Med. 3, 562-566. doi:10.1038/ nm0597-562

Muthalif, M. M., Benter, I. F., Karzoun, N., Fatima, S., Harper, J., Uddin, M. R., et al. (1998). 20-Hydroxyeicosatetraenoic acid mediates calcium/calmodulindependent protein kinase II-induced mitogen-activated protein kinase activation in vascular smooth muscle cells. Proc. Natl. Acad. Sci. U.S.A. 95, 12701-12706. doi:10.1073/pnas.95.21.12701

Nakagawa, K., Holla, V. R., Wei, Y., Wang, W. H., Gatica, A., Wei, S., et al. (2006). Salt-sensitive hypertension is associated with dysfunctional Cyp4a10 gene and kidney epithelial sodium channel. J. Clin. Invest. 116, 1696-1702. doi:10.1172/ jci27546

Nelson, D. R., Zeldin, D. C., Hoffman, S. M., Maltais, L. J., Wain, H. M., and Nebert, D. W. (2004). Comparison of cytochrome P450 (CYP) genes from the mouse and human genomes, including nomenclature recommendations for genes, pseudogenes and alternative-splice variants. Pharmacogenetics 14, 1-18. doi:10. 1097/00008571-200401000-00001

Neve, E. P., and Ingelman-Sundberg, M. (2010). Cytochrome P450 proteins: retention and distribution from the endoplasmic reticulum. Curr. Opin. Drug Discov. Dev 13, 78-85. doi:10.1016/j.cct.2009.10.001

Node, K., Huo, Y., Ruan, X., Yang, B., Spiecker, M., Ley, K., et al. (1999). Antiinflammatory properties of cytochrome $\mathrm{P} 450$ epoxygenase-derived eicosanoids. Science 285, 1276-1279. doi:10.1126/science.285.5431.1276

Ortiz de Montellano, P. R. (2010). Hydrocarbon hydroxylation by cytochrome P450 enzymes. Chem. Rev. 110, 932-948. doi:10.1021/cr9002193

Oscarson, M., McLellan, R. A., Gullstén, H., Agúndez, J. A. G., Benítez, J., Rautio, A., et al. (1999). Identification and characterisation of novel polymorphisms in the CYP2A locus: implications for nicotine metabolism. FEBS Lett. 460, 321-327. doi:10.1016/s0014-5793(99)01364-2

Ouerhani, S., Marrakchi, R., Bouhaha, R., Ben Slama, M. R., Sfaxi, M., Ayed, M., et al. (2008). The role of CYP2D6*4 variant in bladder cancer susceptibility in Tunisian patients. Bull. Cancer 95, E1-E4. doi:10.1684/ bdc. 2008.0583

Ozawa, T., Nishikimi, M., Sugiyama, S., Taki, F., Hayakawa, M., and Shionoya, H. (1988). Cytotoxic activity of leukotoxin, a neutrophil-derived fatty acid epoxide, on cultured human cells. Biochem. Int. 16, 369-373

Panigrahy, D., Edin, M. L., Lee, C. R., Huang, S., Bielenberg, D. R., Butterfield, C. E., et al. (2012). Epoxyeicosanoids stimulate multiorgan metastasis and tumor dormancy escape in mice. J. Clin. Invest. 122, 178-191. doi:10.1172/jci58128

Panigrahy, D., Greene, E. R., Pozzi, A., Wang, D. W., and Zeldin, D. C. (2011). EET signaling in cancer. Canc. Metast. Rev. 30, 525-540. doi:10.1007/s10555-0119315-y

Panigrahy, D., Kaipainen, A., Greene, E. R., and Huang, S. (2010). Cytochrome P450-derived eicosanoids: the neglected pathway in cancer. Canc. Metast. Rev. 29, 723-735. doi:10.1007/s10555-010-9264-x

Pikuleva, I. A. and Waterman, M. R. (2013). Cytochromes p450: roles in diseases. J. Biol. Chem. 288, 17091-17098. doi:10.1074/jbc.r112.431916

Porter, T. D. and Coon, M. J. (1991). Cytochrome P-450. Multiplicity of isoforms, substrates, and catalytic and regulatory mechanisms. J. Biol. Chem. 266, $13469-13472$

Pot, G. K., Geelen, A., van Heijningen, E.-M. B., Siezen, C. L. E., van Kranen, H. J., and Kampman, E. (2008). Opposing associations of serum n-3 and n-6 polyunsaturated fatty acids with colorectal adenoma risk: an endoscopybased case-control study. Int. J. Cancer 123, 1974-1977. doi:10.1002/ijc. 23729

Pozzi, A., and Capdevila, J. H. (2008). PPARalpha ligands as antitumorigenic and antiangiogenic agents. PPAR Res. 2008, 906542. doi:10.1155/2008/906542

Pozzi, A., Ibanez, M. R., Gatica, A. E., Yang, S., Wei, S., Mei, S., et al. (2007). Peroxisomal proliferator-activated receptor- $\alpha$-dependent inhibition of endothelial cell proliferation and tumorigenesis. J. Biol. Chem. 282, 17685-17695. doi:10.1074/jbc.m701429200

Pozzi, A., Popescu, V., Yang, S., Mei, S., Shi, M., Puolitaival, S. M., et al. (2010). The anti-tumorigenic properties of peroxisomal proliferator-activated receptor a are arachidonic acid epoxygenase-mediated. J. Biol. Chem. 285, 12840-12850. doi:10.1074/jbc.m109.081554

Raunio, H., Rautio, A., Gullstén, H., and Pelkonen, O. (2001). Polymorphisms of CYP2A6 and its practical consequences. Br. J. Clin. Pharmacol. 52, 357-363. doi:10.1046/j.0306-5251.2001.01500.x

Ren, J., Chen, G. G., Liu, Y., Su, X., Hu, B., Leung, B. C. S., et al. (2016). Cytochrome P450 1A2 metabolizes $17 \beta$-estradiol to suppress hepatocellular carcinoma. PLoS ONE 11, e0153863. doi:10.1371/journal.pone.0153863

Renaud, H. J., Cui, J. Y., Khan, M., and Klaassen, C. D. (2011). Tissue distribution and gender-divergent expression of 78 cytochrome P450 mRNAs in mice. Toxicol. Sci. 124, 261-277. doi:10.1093/toxsci/kfr240 
Reynald, R. L., Sansen, S., Stout, C. D., and Johnson, E. F. (2012). Structural characterization of human cytochrome P450 2C19. J. Biol. Chem. 287, 44581-44591. doi:10.1074/jbc.m112.424895

Rochat, B., Morsman, J. M., Murray, G. I., Figg, W. D., and McLeod, H. L. (2001). Human CYP1B1 and anticancer agent metabolism: mechanism for tumorspecific drug inactivation? J. Pharmacol. Exp. Therapeut. 296, 537-541.

Rostami-Hodjegan, A., Lennard, M. S., Woods, H. F., and Tucker, G. T. (1998). Meta-analysis of studies of the CYP2D6 polymorphism in relation to lung cancer and Parkinson's disease. Pharmacogenetics 8, 227-238. doi:10.1097/ 00008571-199806000-00005

Roszak, A., Lianeri, M., Sowińska, A., and Jagodziński, P. P (2014). CYP1A1 Ile462Val polymorphism as a risk factor in cervical cancer development in the Polish population. Mol. Diagn. Ther. 18, 445-450. doi:10.1007/s40291-0140095-2

Sachse, C., Brockmöller, J., Bauer, S., and Roots, I. (1999). Functional significance of a $\mathrm{C} \rightarrow \mathrm{A}$ polymorphism in intron 1 of the cytochrome $\mathrm{P} 450 \mathrm{CYP} 1 \mathrm{~A} 2$ gene tested with caffeine. Br. J. Clin. Pharmacol. 47, 445-449. doi:10.1046/j.13652125.1999.00898.x

Sausville, L. N., Gangadhariah, M. H., Chiusa, M., Mei, S., Wei, S., Zent, R., et al. (2018). The cytochrome P450 slow metabolizers CYP2C9 ${ }^{*} 2$ and CYP2C ${ }^{*} 3$ directly regulate tumorigenesis via reduced epoxyeicosatrienoic acid production. Cancer Res. 78, 4865-4877. doi:10.1158/0008-5472.can-17-3977

Sausville, L. N., Williams, S. M., and Pozzi, A. (2019). Cytochrome P450 epoxygenases and cancer: a genetic and a molecular perspective. Pharmacol. Ther. 196, 183-194. doi:10.1016/j.pharmthera.2018.11.009

Schmelzer, K. R., Inceoglu, B., Kubala, L., Kim, I.-H., Jinks, S. L., Eiserich, J. P., et al. (2006). Enhancement of antinociception by coadministration of nonsteroidal anti-inflammatory drugs and soluble epoxide hydrolase inhibitors. Proc. Natl. Acad. Sci. U.S.A. 103, 13646-13651. doi:10.1073/pnas.0605908103

Seow, A., Zhao, B., Lee, E. J. D., Poh, W.-T., Teh, M., Eng, P., et al. (2001). Cytochrome P4501A2 (CYP1A2) activity and lung cancer risk: a preliminary study among Chinese women in Singapore. Carcinogenesis 22, 673-677. doi:10. 1093/carcin/22.4.673

Serhan, C. N., Chiang, N., and Van Dyke, T. E. (2008). Resolving inflammation: dual anti-inflammatory and pro-resolution lipid mediators. Nat. Rev. Immunol. 8, 349-361. doi:10.1038/nri2294

Seubert, J. M., Zeldin, D. C., Nithipatikom, K., and Gross, G. J. (2007). Role of epoxyeicosatrienoic acids in protecting the myocardium following ischemia/ reperfusion injury. Prostag. Other Lipid Mediat. 82, 50-59. doi:10.1016/j. prostaglandins.2006.05.017

Simpson, A. E. (1997). The cytochrome P450 4 (CYP4) family. Gen. Pharmacol. 28, 351-359. doi:10.1016/S0306-3623(96)00246-7

Singh, V., Rastogi, N., Sinha, A., Kumar, A., Mathur, N., and Singh, M. P. (2007). A study on the association of cytochrome-P450 $1 \mathrm{~A} 1$ polymorphism and breast cancer risk in north Indian women. Breast Canc. Res. Treat. 101, 73-81. doi:10. 1007/s10549-006-9264-2

Siraj, A. K., Ibrahim, M., Al-Rasheed, M., Abubaker, J., Bu, R., Siddiqui, S. U., et al. (2008). Polymorphisms of selected xenobiotic genes contribute to the development of papillary thyroid cancer susceptibility in Middle Eastern population. BMC Med. Genet. 9, 61. doi:10.1186/1471-2350-9-61

Sistonen, J., Fuselli, S., Palo, J. U., Chauhan, N., Padh, H., and Sajantila, A. (2009). Pharmacogenetic variation at CYP2C9, CYP2C19, and CYP2D6 at global and microgeographic scales. Pharmacogen. Genom. 19, 170-179. doi:10.1097/fpc. 0b013e32831ebb30

Snyder, G. D., Yadagiri, P., and Falck, J. R. (1989). Effect of epoxyeicosatrienoic acids on growth hormone release from somatotrophs. Am. J. Physiol.Endocrinol. Metabol. 256, E221-E226. doi:10.1152/ajpendo.1989.256.2.e221

Sobti, R. C., Onsory, K., Al-Badran, A. I., Kaur, P., Watanabe, M., Krishan, A., et al. (2006). CYP17, SRD5A2, CYP1B1, and CYP2D6 gene polymorphisms with prostate cancer risk in North Indian population. DNA Cell Biol. 25, 287-294. doi:10.1089/dna.2006.25.287

Sokolowska, M., Rovati, G. E., Diamant, Z., Untersmayr, E., Schwarze, J., Lukasik, Z., et al. (2020). Current perspective on eicosanoids in asthma and allergic diseases-EAACI Task Force consensus report, part I. Allergy doi:10.1111/all. 14295

Stark, K., Dostalek, M., and Guengerich, F. P. (2008). Expression and purification of orphan cytochrome P450 4X1 and oxidation of anandamide. FEBS J. 275, 3706-3717. doi:10.1111/j.1742-4658.2008.06518.x
Strange, R. C., Ellison, T., Ichii-Jones, F., Bath, J., Hoban, P., Lear, J. T., et al. (1999). Cytochrome P450 CYP2D6 genotypes: association with hair colour, Breslow thickness and melanocyte stimulating hormone receptor alleles in patients with malignant melanoma. Pharmacogenetics 9, 269-276. doi:10.1097/00008571199906000-00001

Sugawara, T., Nomura, E., Sagawa, T., Sakuragi, N., and Fujimoto, S. (2003). CYP1A1 polymorphism and risk of gynecological malignancy in Japan. Int. J. Gynecol. Cancer 13, 785-790. doi:10.1136/ijgc-00009577-20031100000009

Tan, Y. H., Sidik, S. M., Husain, S. N. A. S., Lye, M. S., and Chong, P. P. (2016). CYP1A1 MspI polymorphism and cervical carcinoma risk in the multi-ethnic population of Malaysia: a case-control study. Asian Pac. J. Cancer Prev. APJCP 17, 57-64. doi:10.7314/apjcp.2016.17.1.57

Thelen, K., and Dressman, J. B. (2009). Cytochrome P450-mediated metabolism in the human gut wall. J. Pharm. Pharmacol. 61, 541-558. doi:10.1211/jpp.61.05. 0002

Totani, Y., Saito, Y., Ishizaki, T., Sasaki, F., Ameshima, S., and Miyamori, I. (2000). Leukotoxin and its diol induce neutrophil chemotaxis through signal transduction different from that of fMLP. Eur. Respir. J. 15, 75-79. doi:10. $1183 / 09031936.00 .15107500$

Tsuneoka, Y., Fukushima, K., Matsuo, Y., Ichikawa, Y., and Watanabe, Y. (1996). Genotype analysis of the CYP2C19 gene in the Japanese population. Life Sci. 59, 1711-1715. doi:10.1016/s0024-3205(96)00507-3

Tuncer, S., and Banerjee, S. (2015). Eicosanoid pathway in colorectal cancer: recent updates. W. J. Gastroenterol. 21, 11748-11766. doi:10.3748/wjg.v21.i41.11748

Ulu, A., Stephen Lee, K. S., Miyabe, C., Yang, J., Hammock, B. G., Dong, H., et al. (2014) An omega-3 epoxide of docosahexaenoic acid lowers blood pressure in angiotensin-II-dependent hypertension. J. Cardiovasc. Pharmacol. 64, 87-99. doi:10.1097/fjc.0000000000000094

Van Booven, D., Marsh, S., McLeod, H., Carrillo, M. W., Sangkuhl, K., Klein, T. E., and Altman, R. B. (2010). Cytochrome P450 2C9-CYP2C9. Pharmacogen. Genom. 20, 277-281. doi:10.1097/FPC.0b013e3283349e84

VanRollins, M., Baker, R. C., Sprecher, H. W., and Murphy, R. C. (1984). Oxidation of docosahexaenoic acid by rat liver microsomes. J. Biol. Chem. 259, 5776-5783.

VanRollins, M., Frade, P. D., and Carretero, O. A. (1988). Oxidation of 5,8,11,14,17-eicosapentaenoic acid by hepatic and renal microsomes. Biochim. Biophys. Acta Gen. Subj. 966, 133-149. doi:10.1016/0304-4165(88) 90137-7

Wadelius, M., Autrup, J. L., Stubbins, M. J., Andersson, S.-O., Johansson, J.-E., Wadelius, C., et al. (1999). Polymorphisms in NAT2, CYP2D6, CYP2C19 and GSTP1 and their association with prostate cancer. Pharmacogenetics 9, 333-340. doi:10.1097/00008571-199906000-00008

Wang, D., and Dubois, R. N. (2006). Prostaglandins and cancer. Gut 55, 115-122. doi:10.1136/gut.2004.047100

Wang, H., Song, K., Chen, Z., and Yu, Y. (2013). Poor metabolizers at the cytochrome P450 $2 \mathrm{C} 19$ loci is at increased risk of developing cancer in Asian populations. PLoS ONE 8, e73126. doi:10.1371/journal.pone.0073126

Wang, L. N., Wang, F., Liu, J., Jin, Y. H., Fang, C., and Ren, X. Q. (2017). CYP1A1 Ile462Val polymorphism is associated with cervical cancer risk in Caucasians not Asians: a meta-analysis. Front. Physiol. 8, 1081. doi:10.3389/fphys.2017. 01081

Wang, W., Yang, J., Edin, M. L., Wang, Y., Luo, Y., Wan, D., et al. (2019). Targeted metabolomics identifies the cytochrome P450 monooxygenase eicosanoid pathway as a novel therapeutic target of colon tumorigenesis. Cancer Res 79, 1822-1830. doi:10.1158/0008-5472.can-18-3221

Wei, X., Zhang, D., Dou, X., Niu, N., Huang, W., Bai, J., et al. (2014). Elevated 14,15- epoxyeicosatrienoic acid by increasing of cytochrome P450 2C8, 2C9 and $2 J 2$ and decreasing of soluble epoxide hydrolase associated with aggressiveness of human breast cancer. BMC Cancer 14, 841. doi:10.1186/1471-2407-14-841

Wolf, C. R., Smith, C. A. D., Gough, A. C., Moss, J. E., Vallis, K. A., Howard, G., et al. (1992). Relationship between the debrisoquine hydroxylase polymorphism and cancer susceptibility. Carcinogenesis 13, 1035-1038. doi:10.1093/carcin/13.6.1035

Womack, C. J., Saunders, M. J., Bechtel, M. K., Bolton, D. J., Martin, M., et al. (2012). The influence of a CYP1A2 polymorphism on the ergogenic effects of caffeine. J. Int. Soc. Sports Nutr. 9, 7. doi:10.1186/1550-2783-9-7

Wongpratate, M., Ishida, W., Phuthong, S., Natphopsuk, S., and Ishida, T. (2020), Genetic polymorphisms of the human cytochrome P450 1A1 (CYP1A1) and 
cervical cancer susceptibility among Northeast Thai women. Asian Pac. J. Cancer Prev. APJCP 21, 243-248. doi:10.31557/apjcp.2020.21.1.243

Wu, B., Iwakiri, R., Ootani, A., Tsunada, S., Fujise, T., Sakata, Y., et al. (2004). Dietary corn oil promotes colon cancer by inhibiting mitochondria-dependent apoptosis in azoxymethane-treated rats. Exp. Biol. Med. 229, 1017-1025. doi:10. $1177 / 153537020422901005$

Wu, B., Liu, K., Huang, H., Yuan, J., Yuan, W., Wang, S., et al. (2013). MspI and Ile462Val polymorphisms in CYP1A1 and overall cancer risk: a meta-analysis. PLoS ONE 8, e85166. doi:10.1371/journal.pone.0085166

Wu, S., Chen, W., Murphy, E., Gabel, S., Tomer, K. B., Foley, J., et al. (1997). Molecular cloning, expression, and functional significance of a cytochrome P450 highly expressed in rat heart myocytes. J. Biol. Chem. 272, 12551-12559. doi:10.1074/jbc.272.19.12551

Xu, M., Ju, W., Hao, H., Wang, G., and Li, P. (2013). Cytochrome P450 2J2: distribution, function, regulation, genetic polymorphisms and clinical significance. Drug Metabol. Rev. 45, 311-352. doi:10.3109/03602532.2013. 806537

Xu, X., Zhang, X. A., and Wang, D. W. (2011). The roles of CYP450 epoxygenases and metabolites, epoxyeicosatrienoic acids, in cardiovascular and malignant diseases. Adv. Drug Deliv. Rev. 63, 597-609. doi:10.1016/j. addr.2011.03.006

Yadav, S. S., Seth, S., Khan, A. J., Maurya, S. S., Dhawan, A., Pant, S., et al. (2014). Association of polymorphism in cytochrome P450 2C9 with susceptibility to head and neck cancer and treatment outcome. Appl. Transl. Genom. 3, 8-13. doi:10.1016/j.atg.2013.07.002

Yan, F., Xu, J.-F., Liu, X.-f., and Li, X.-H. (2014). Interaction between smoking and CYP2C19*3 polymorphism increased risk of lung cancer in a Chinese population. Tumor Biol. 35, 5295-5298. doi:10.1007/s13277-014-1689-3

Yanai, R., Mulki, L., Hasegawa, E., Takeuchi, K., Sweigard, H., Suzuki, J., et al. (2014). Cytochrome P450-generated metabolites derived from $\omega-3$ fatty acids attenuate neovascularization. Proc. Natl. Acad. Sci. U.S.A. 111, 9603-9608. doi:10.1073/pnas.1401191111

Yang, S., Wei, S., Pozzi, A., and Capdevila, J. H. (2009). The arachidonic acid epoxygenase is a component of the signaling mechanisms responsible for VEGF-stimulated angiogenesis. Arch. Biochem. Biophys. 489, 82-91. doi:10. 1016/j.abb.2009.05.006

Yu, P. J., Chen, W. G., Feng, Q. L., Chen, W., Jiang, M. J., and Li, Z. Q. (2015). Association between CYP1B1 gene polymorphisms and risk factors and susceptibility to laryngeal cancer. Med. Sci. Mon. Int. Med. J. Exp. Clin. Res. 21, 239-245. doi:10.12659/msm.893606

Yu, W., Chen, L., Yang, Y.-Q., Falck, J. R., Guo, A. M., Li, Y., et al. (2011). Cytochrome $\mathrm{P} 450 \omega$-hydroxylase promotes angiogenesis and metastasis by upregulation of VEGF and MMP-9 in non-small cell lung cancer. Cancer Chemother. Pharmacol. 68, 619-629. doi:10.1007/s00280-010-1521-8

Zanger, U. M., and Schwab, M. (2013). Cytochrome P450 enzymes in drug metabolism: regulation of gene expression, enzyme activities, and impact of genetic variation. Pharmacol. Ther. 138, 103-141. doi:10.1016/j.pharmthera. 2012.12.007

Zeldin, D. C., Foley, J., Boyle, J. E., Moomaw, C. R., Tomer, K. B., Parker, C., et al. (1997). Predominant expression of an arachidonate epoxygenase in islets of Langerhans cells in human and rat pancreas. Endocrinology 138, 1338-1346. doi:10.1210/endo.138.3.4970

Zeldin, D. C., Wei, S. Z., Falck, J. R., Hammock, B. D., Snapper, J. R., and Capdevila, J. H. (1995). Metabolism of epoxyeicosatrienoic acids by cytosolic epoxide hydrolase: substrate structural determinants of asymmetric catalysis. Arch. Biochem. Biophys. 316, 443-451. doi:10. 1006/abbi.1995.1059

Zhang, B., Cao, H., and Rao, G. N. (2006). Fibroblast growth factor-2 is a downstream mediator of phosphatidylinositol 3-kinase-Akt signaling in 14,15-epoxyeicosatrienoic acid-induced angiogenesis. J. Biol. Chem. 281, 905-914. doi:10.1074/jbc.m503945200

Zhang, G., Kodani, S., and Hammock, B. D. (2014a). Stabilized epoxygenated fatty acids regulate inflammation, pain, angiogenesis and cancer. Prog. Lipid Res. 53, 108-123. doi:10.1016/j.plipres.2013.11.003

Zhang, G., Panigrahy, D., Hwang, S. H., Yang, J., Mahakian, L. M., Wettersten, H. I., et al. (2014b). Dual inhibition of cyclooxygenase-2 and soluble epoxide hydrolase synergistically suppresses primary tumor growth and metastasis. Proc. Natl. Acad. Sci. U.S.A. 111, 11127-11132. doi:10.1073/pnas.1410432111

Zhang, G., Panigrahy, D., Mahakian, L. M., Yang, J., Liu, J.-Y., Stephen Lee, K. S., et al. (2013a). Epoxy metabolites of docosahexaenoic acid (DHA) inhibit angiogenesis, tumor growth, and metastasis. Proc. Natl. Acad. Sci. U.S.A. 110, 6530-6535. doi:10.1073/pnas.1304321110

Zhang, W., Li, H., Dong, H., Liao, J., Hammock, B. D., and Yang, G. Y. (2013b). Soluble epoxide hydrolase deficiency inhibits dextran sulfate sodium-induced colitis and carcinogenesis in mice. Anticancer Res. 33, 5261-5271

Zhao, Y., Chen, Z.-X., Rewuti, A., Ma, Y.-S., Wang, X.-F., Xia, Q., et al. (2013). Quantitative assessment of the influence of cytochrome P450 1A2 gene polymorphism and colorectal cancer risk. PLOS ONE 8, e71481. doi:10.1371/ journal.pone. 0060607

Zheng, J., Plopper, C. G., Lakritz, J., Storms, D. H., and Hammock, B. D. (2001) Leukotoxin-diol. Am. J. Respir. Cell Mol. Biol. 25, 434-438. doi:10.1165/ajrcmb. 25.4.4104

Zheng, Y., Xu, Y., Zhou, B. Y., Sun, L., Yu, P. B., Zhang, L., et al. (2018). CYP $34^{*} 1 \mathrm{~B}$ polymorphism and cancer risk: a meta-analysis based on 55 case-control studies. Ann. Clin. Lab. Sci. 48, 538-545

Zhou, J., Wen, Q., Li, S.-F., Zhang, Y.-F., Gao, N., Tian, X., et al. (2016). Significant change of cytochrome P450s activities in patients with hepatocellular carcinoma. Oncotarget 7, 50612-50623. doi:10.18632/oncotarget.9437

Zhou, X., Gu, Y., Wang, D.-N., Ni, S., Yan, J., and Zou, S. (2013). Eight functional polymorphisms in the estrogen receptor 1 gene and endometrial cancer risk: a meta-analysis. PLoS ONE 8, e60851. doi:10.1371/journal. pone. 0066865

Zhu, Z. Y., Mu, Y. Q., Fu, X. M., Li, S. M., and Zhao, F. X. (2011). Association of CYP1B1 gene polymorphisms and the positive expression of estrogen alpha and estrogen beta with endometrial cancer risk. Eur. J. Gynaecol. Oncol. 32, 188-191. doi:10.1017/S0008423906459965

Conflict of Interest: The authors declare that the research was conducted in the absence of any commercial or financial relationships that could be construed as a potential conflict of interest.

Copyright $\odot 2020$ Luo and Liu. This is an open-access article distributed under the terms of the Creative Commons Attribution License (CC BY). The use, distribution or reproduction in other forums is permitted, provided the original author(s) and the copyright owner(s) are credited and that the original publication in this journal is cited, in accordance with accepted academic practice. No use, distribution or reproduction is permitted which does not comply with these terms. 